\title{
The family of box ACA small nucleolar RNAs is defined by an evolutionarily conserved secondary structure and ubiquitous sequence elements essential for RNA accumulation
}

\author{
Philippe Ganot, Michèle Caizergues-Ferrer, and Tamás Kiss ${ }^{1}$ \\ Laboratoire de Biologie Moléculaire Eucaryote du Centre National de la Recherche (CNRS), Université Paul Sabatier, \\ 31062 Toulouse CEDEX, France
}

\begin{abstract}
Eukaryotic cells contain a large number of small nucleolar RNAs (snoRNAs). A major family of snoRNAs features a consensus ACA motif positioned 3 nucleotides from the $3^{\prime}$ end of the RNA. In this study we have characterized nine novel human ACA snoRNAs (U64-U72). Structural probing of U64 RNA followed by systematic computer modeling of all known box ACA snoRNAs revealed that this class of snoRNAs is defined by a phylogenetically conserved secondary structure. The ACA snoRNAs fold into two hairpin structures connected by a single-stranded hinge region and followed by a short 3' tail. The hinge region carries an evolutionarily conserved sequence motif, called box $H$ (consensus, AnAnnA). The $H$ box, probably in concert with the flanking helix structures and the ACA box characterized previously, plays an essential role in the accumulation of human U64 intronic snoRNA. The correct processing of a yeast ACA snoRNA, snR36, in mammalian cells demonstrated that the cis- and trans-acting elements required for processing and accumulation of ACA snoRNAs are evolutionarily conserved. The notion that ACA snoRNAs share a common secondary structure and conserved box elements that likely function as binding sites for common proteins (e.g., GAR1) suggests that these RNAs possess closely related nucleolar functions.
\end{abstract}

[Key Words: Small nucleolar RNAs; box ACA snoRNAs, intron-encoded RNAs; RNA processing; nucleolus]

Received December 20, 1996; revised version accepted February 18, 1997.

In eukaryotic cells, maturation of rRNAs takes place in the nucleolus. The $18 \mathrm{~S}, 5.8 \mathrm{~S}$, and $25 / 28 \mathrm{~S}$ rRNAs are synthesized as a large precursor RNA (pre-rRNA) that carries long external and internal spacer sequences. Shortly after transcription, many nucleotides in the coding regions of pre-rRNA are methylated at the 2 - $O$-hydroxyl position and numerous $U$ residues are converted into pseudouridines (Maden 1990; Eichler and Craig 1995). The covalently modified pre-rRNA is than processed into mature rRNAs through a series of endo- and exonucleolytic cleavages (Eichler and Craig 1995; Venema and Tollervey 1995; Sollner-Webb et al. 1996).

The nucleolus contains a large number of snoRNAs. More than 80 distinct small nucleolar RNA (snoRNA) sequences have been identified in vertebrate and yeast cells (Maxwell and Fournier 1995; Balakin et al. 1996; Kiss-László et al. 1996; Nicoloso et al. 1996; Tycowski et al. 1996). Many of these snoRNAs have been demon-

${ }^{1}$ Corresponding author.

E-MAIL tamas@ibcg.biotoul.fr; FAX (33) 561335886. strated to function in processing or modification of prerRNA (for review, see Eichler and Craig 1995; Maxwell and Fournier 1995; Venema and Tollervey 1995; see also Kiss-László et al. 1996). The snoRNAs are either transcribed by RNA polymerase II (Pol II) from independent genes or they are processed from intron regions of premRNAs (for review, see Maxwell and Fournier 1995). The mature intron-encoded snoRNAs possess monophosphates at their $5^{\prime}$ ends (Kiss and Filipowicz 1993; Tycowski et al. 1993), whereas the 5' termini of Pol IItranscribed snoRNAs are blocked by trimethylguanosine caps (Maxwell and Fournier 1995).

The snoRNAs are complexed with proteins and form small ribonucleoprotein particles (snoRNPs) (for review, see Maxwell and Fournier 1995; Sollner-Webb et al. 1996). Great subsets of snoRNAs share common associated proteins and conserved sequence elements that likely represent binding sites for snoRNP proteins (Maxwell and Fournier 1995; Balakin et al. 1996). Most snoRNAs characterized to date contain two short conserved sequence elements, called box $\mathrm{C}$ and $\mathrm{D}$ (Maxwell and Fournier 1995; Sollner-Webb et al. 1996). The C and D 
boxes appear always jointly. They are required for metabolic stability of snoRNAs (Huang et al. 1992; Peculis and Steitz 1994; Terns et al. 1995) and for processing of the intron-encoded members of this class of snoRNAs (Caffarelli et al. 1996; Watkins et al. 1996; Xia et al. 1997). The $C$ and D boxes of vertebrate snoRNAs are required, probably indirectly (Lübben et al. 1993); for binding an evolutionarily conserved nucleolar protein, fibrillarin (Baserga and Steitz 1991; Peculis and Steitz 1994). Consistent with this, the C and D box-containing snoRNAs are always found in snoRNPs precipitable with antibodies directed against fibrillarin (Tyc and Steitz 1989; Maxwell and Fournier 1995; Kiss-László et al. 1996).

The C and D box-containing, fibrillarin-associated snoRNAs function in various steps of pre-rRNA maturation. The U3 snoRNA is required for an early cleavage in the $5^{\prime}$ external transcribed spacer (Kass et al. 1990; Hughes and Ares 1991; Mougey et al. 1993) and also for subsequent formation of mature 18S rRNA (Savino and Gerbi 1990; Hughes and Ares 1991). Likewise, the U14 and U22 snoRNAs are essential for the accumulation of $18 \mathrm{~S}$ rRNA (Li et al. 1990; Tycowski et al. 1994), whereas the U8 snoRNA is implicated in the processing of $5.8 \mathrm{~S}$ and 28S rRNAs (Peculis and Steitz 1993). More recently, a large subset of box C/D snoRNAs have been demonstrated to function as guide RNAs in site-specific ribose methylation of pre-rRNAs (Kiss-László et al. 1996; Nicoloso et al. 1996).

The 7-2/MRP RNA, the RNA component of RNase $M R P$, represents a unique member of snoRNAs. The RNase MRP is an endoribonuclease that cleaves yeast pre-rRNA in a region upstream of the 5.8S rRNA (Schmitt and Clayton 1993; Chu et al. 1994; Lygerou et al. 1996). The 7-2/MRP RNA is structurally related to the nucleoplasmic RNase P RNA (Forster and Altman 1990; Schmitt et al. 1993), and the RNase MRP and RNase $\mathrm{P}$ particles share common antigenic properties (Gold et al. 1989; Lygerou et al. 1994).

Recently, it was discovered that all yeast and vertebrate snoRNAs lacking $\mathrm{C}$ and $\mathrm{D}$ boxes, with the exception of 7-2/MRP RNA, contain a consensus ACA triplet located 3 nucleotides before the 3 ' end of the RNA (Balakin et al. 1996). Mutational analysis demonstrated that the ACA box, together with an adjacent upstream helical segment, is required for accumulation of a yeast ACA snoRNA, snR11 (Balakin et al. 1996). The yeast ACA snoRNAs have been reported to share two common associated nucleolar proteins, fibrillarin (NOP1) and GAR1 (Schimmang et al. 1989; Balakin et al. 1996). Fibrillarin has been suggested to be common to all yeast snoRNPs, with the exception of 7-2/MRP. The GAR1 protein, an essential glycine/arginine-rich nucleolar protein /Girard et al. 1992), seems to be specific to the ACA box-containing snoRNAs (Balakin et al. 1996). Two yeast ACA snoRNAs, snR10 and snR11, are precipitable with antibodies directed against another nucleolar protein, SSB1 (Clark et al. 1990). It is unclear whether any of these proteins bind directly to the ACA box.

Little is known about the nucleolar function of ACA
snoRNAs. Yeast snR30 is required for cell viability and processing of 18S rRNA (Bally et al. 1988; Morrissey and Tollervey 1993). Yeast strains lacking an intact copy of the snR10 gene are slightly impaired in growth (Tollervey and Guthrie 1985; Tollervey 1987). However, a long list of ACA snoRNAs tested by genetic depletion turned out to be dispensable in yeast (Maxwell and Fournier 1995; Balakin et al. 1996 and references therein).

In this work characterization of nine novel human ACA snoRNAs, followed by structural modeling of ACA snoRNAs of phylogenetically distant origin, reveals that this class of snoRNAs is defined by a conserved hairpinhinge-hairpin-tail core structure. We also describe a novel ubiquitous sequence motif for ACA snoRNA, designated as box $\mathrm{H}$. The $\mathrm{H}$ box is positioned in the singlestranded hinge region of ACA snoRNAs and is required for RNA accumulation.

\section{Results}

Identification of novel intron-encoded ACA snoRNAs from human HeLa cells

Mammalian snoRNAs, with the exception of U3, U8, U13, and 7-2/MRP RNA, are processed from introns of pre-mRNAs (Maxwell and Fournier 1995). To identify novel snoRNAs, we recently constructed a cDNA library of human intron-encoded snoRNAs (Kiss-László et al. 1996). Briefly, HeLa snoRNAs carrying $5^{\prime}$ monophosphate and $3^{\prime} \mathrm{OH}$ ends were tagged at both termini with an oligoribonucleotide in a T4 RNA ligase-catalyzed reaction. The double-tagged RNAs were amplified by RTPCR, cloned, and characterized by sequence analyses. In addition to many $\mathrm{C}$ and $\mathrm{D}$ box-containing snoRNAs (Kiss-László et al. 1996), we identified nine novel snoRNAs, referred to as U64-U72, which lack the box C and $\mathrm{D}$ motifs and show no significant sequence similarities to any known small nuclear RNA (Fig. 1). Because the new snoRNAs contain ACA or AUA (U72) triplets located 3 nucleotides before the $3^{\prime}$ end, we conclude that they represent novel members of the family of human ACA snoRNAs. The expression of the new snoRNAs in human HeLa cells was verified by Northern blot analyses (data not shown) and RNase $A / T_{1}$ mappings (Fig. 2A).

Searches of the GenBank database revealed that a perfect copy of U70 snoRNA is present in the third intron of a human housekeeping gene, Q1Z 7F5 (Van den Ouweland et al. 1992; GenBank accession no. M81806). Sequences $89 \%$ and $74 \%$ homologous to U72 snoRNA were found in the fourth intron of mouse (Wiedemann and Perry 1984; GenBank accession no. K02928) and chicken (Nakasone et al. 1993; GenBank accession no. D14521) L30 ribosomal protein genes, respectively. The sequences of U64 and U67 snoRNAs had been deposited into the database as parts of expressed sequence tags (ESTs) (GenBank accession nos. T68031 and H46901, respectively|. Because the two EST sequences contain internal portions of the cDNA sequences reported either for human ribosomal protein S4 (U64) (Slynn et al. 1990) or for human translation initiation factor eIF4aI (U67) 
ACUCUCUCGG CUCUGCAUAG UUGCACUUGG CUUCACCCGU GUGACUUUCG UAACGGGGAG AGAGAGAAAA GAUCUCCUCA GGACCUCGGA UGGGCCUUAC UGUGGCCUCU CUUUCCUUGA GGGGUGCAAC AGGC

UCAGCCACCC GCCACUGCAC CUGACCAGGU CUCUGUUGGC UGGUGCAAUC CAGUGGUGAG CUGAUAGUAA ACCCCAGCUU AGGAAACAGG GUUGUUCUUC AUGUGGAUGA CUCUGUGCCG AAAGCAUGGG AACAGCU

GUGCAAACUC GAUCACUAGC UCUGCGUGAU GUGGCAGAAG CAAAGGGAAC CAGGUUUGCA AAAGUAACUG UGGUGAUGGA AAUGUGUUAG CCUCAGACAC UACUGAGGUG GUUCUUUCUA UCCUAGUACA GUC

AUCCAAGGUG AUUCCCUCUC CAAGGGGACA UCAGUGCCUC UCAGGAAAGU AGCAGCUUGG AAUAGAAUCU GGCAUGCCUA AGGCCUUUGG GGAACUGGGA UGCUUAUUUC CUCUGCCUUC CUUGGCUGCC CACAUGG

AUUGCACCUA AACCCAAGAA UCACUGUUUC UUAUAGCGGU GGUUUAAACA GAGGUGCAAA CAGCAAGCGg AUCUUGUCGC CUUUGGGGGG CUGUGGCCGU GCCCCUCAAA GUGAAUUUGG AGGUUCCACA ACU

AAAGCAGGUU GCAAUUACAG UGCUUCAUUU UGUGGAAGUA CUGCCAUUAU CCUGCUGAAA GAAAAGCCGU GUUAAUCAUU UUUGAUUUUG CCUUUAUGAG GGUAAAAUCA UGACAGAUUG ACAUGGACAA UU

CCGCAGCCAA UUAAGCCGAC UGAGUUCCUU UCCUCAUGGG GACCCAGUGU GCGAUGGCUG CACACAGCAG CUUCCUUGGU AGUGUACGCA GCCUGUUGGU UGUAUGGGUU GCUCUAAGGG ACCUUGGAGA CAGGC

CUCCUGCAUC CGAAAGUGAU CAUAGGCUGC CUGUGCCUAG GUCAUUGAUA GUGCAGGGAG AgGAACGCUG AAAGAGGUUG UCCCCGUGUU UGGAGGGUCC ACCCUAUCCC AUCCGAACCC UGAAGCUUUC ACACAACU

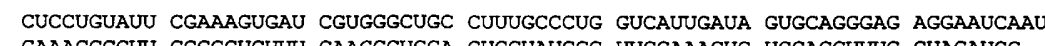
GAAAGCGCUU CCCCGUGUUU GAAGGGUCCA CUCCUAUCCC UUCCAAACUC UGGAGCUUUC GUACAUGC

CUGCGAAUAU UCUCGCUGUU CUGAUUUUGU AAUAGUCAGG ACAGGCUAAA CAUUCGCUAU AUUAAGACCA UGCAUGUGUC CCCAAACCUA GUUCUUUCCC UAGGUCUGGU UUCAUAAAUG CUGGUGAUAA AC

Figure 1. Sequences of novel human snoRNAs. The conserved ACA or AUA motifs located three nucleotides before the $3^{\prime}$ end of the RNAs are underlined. The sequence and the $5^{\prime}$ terminus of each snoRNA was verified by RNase protection and primer extension. The sequence of U64, U65, U66, U69, and U70 snoRNAs was confirmed by sequencing of at least two cDNA clones obtained from independent PCR reactions.
(Kim et al. 1993), they likely represent fragments of premRNAs awaiting splicing and snoRNA excision. These observations, coupled with the demonstration that U64, U65, and U66 RNAs are correctly processed from an intron of the human $\beta$-globin pre-mRNA (see below), suggest that most, if not all, of the new human ACA snoRNAs are generated by intron processing.
The novel snoRNAs are associated with higher order nucleolar structures

Although all box ACA RNAs are believed to reside in the nucleolus, this has been substantiated by cell fractionation experiments only for a few mammalian snoRNAs (Kiss and Filipowicz 1993; Ruff et al. 1993; Kiss et al.
A

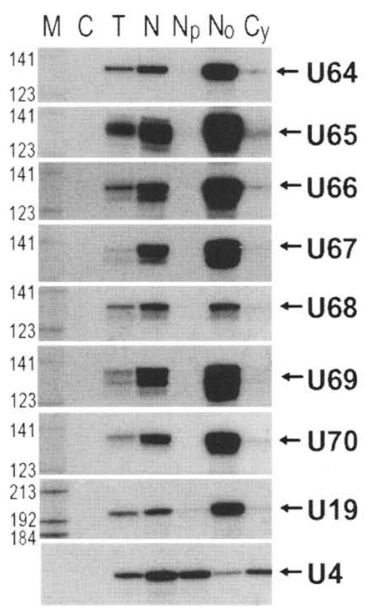

B

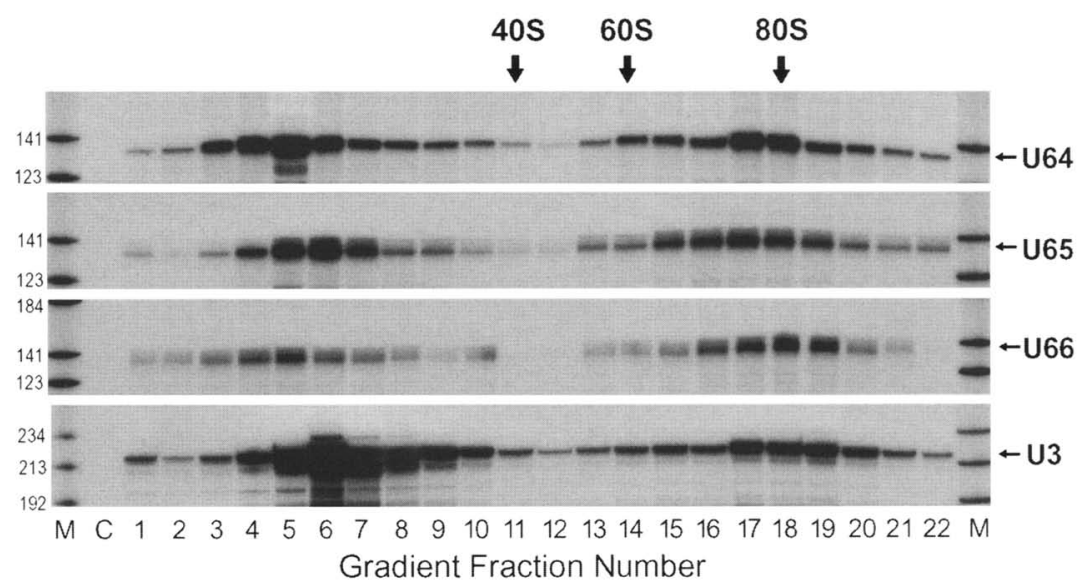

Figure 2. Subcellular localization and sedimentation analyses of snoRNAs. $(A)$ Intracellular localization of snoRNAs in HeLa cells. RNA samples isolated either from HeLa cells $(\mathrm{T})$, or from nuclear $(\mathrm{N})$, nucleoplasmic ( $\mathrm{Np})$, nucleolar (No), and cytoplasmic $(\mathrm{Cy})$ fractions of HeLa cells were analyzed by RNase A/ $\mathrm{T}_{1}$ mapping using sequence-specific antisense RNA probes as indicated at right. (Lane C) Control mapping with Escherichia coli tRNA; (lane M) size marker (a mixture of HaeIII- and TaqI-digested pBR322). Mappings with snoRNA-specific probes and with the U4-specific probe were autoradiographed for 16 and $2 \mathrm{hr}$, respectively. The multiple bands for U65, U66, U67, and U69 snoRNAs likely represent artifacts of RNase mapping. Neither Northern nor primer extension analyses identified sequence variants of these snoRNAs (data not shown). (B) Sedimentation analyses of human U64, U65, U66, and U3 snoRNAs. HeLa cellular extract was fractionated on a 10\%-30\% glycerol gradient. The gradient was divided into 22 fractions. RNA isolated from each fraction was analyzed by RNase A/T mapping using antisense RNA probes specific for U64, U65, U66, or U3 snoRNA. Ten times more RNA was used to probe U64-U66 snoRNAs than to probe U3. HeLa ribosome markers (indicated at top) were run in parallel gradients. (Lanes $C$ and $M$ ) Control mappings and size markers. 
1996). The nucleolar origin of yeast ACA RNAs was inferred from their resistance to extraction with low salt buffers or Triton X-114 (Balakin et al. 1993, 1996; Morissey and Tollervey 1993; Samarsky et al. 1995). Subcellular fractionation of HeLa cells indicated that the newly identified human ACA snoRNAs (U64-U70) are highly enriched in the nucleoli, like the control U19 snoRNA (Kiss et al. 1996), and in contrast to the spliceosomal U4 snRNA, they are not present in the nucleoplasmic fraction (Fig. 2A). On the basis of the previously reported copy number of $U 4$ snRNA in HeLa cells $(200,000$ copies per cell) (Reddy and Busch 1988), the cellular abundance of the novel ACA snoRNAs was estimated to be between 8000 (U70) and 12,000 (U65) copies per cell.

In mammalian cells, many snoRNPs that participate in pre-rRNA processing have been shown to be associated with higher order nucleolar complexes that sediment at 40S-80S and probably represent ribosomal particles undergoing maturation in the nucleolus (Epstein et al. 1984; Tyc and Steitz 1989; Kiss and Filipowicz 1993; Kiss et al. 1996). We have investigated whether the new ACA snoRNAs are associated with large structures by fractionation of HeLa cellular extracts in nondenaturing glycerol gradients (Fig. 2B). About half of the U64, U65, and U66 snoRNAs sedimented in 10S-15S monoparticlelike structures. The other half of these snoRNAs was found in large higher order structures that possess sedi- mentation properties similar to the previously characterized $~ 80$ S nucleolar particles containing U3 snoRNA (Epstein et al. 1984; Tyc and Steitz 1989; Kiss et al. 1992).

\section{Secondary structure of human U64 snoRNA}

Information available about the structure of mammalian and yeast ACA snoRNAs suggests that these RNAs possess compact secondary structures (Balakin et al. 1996; Kiss et al. 1996). Because the novel human snoRNAs are significantly shorter (132-139 nucleotides) (Fig. 1) than most of the previously identified mammalian and yeast ACA RNAs (180-600 nucleotides) (Maxwell and Fournier 1995; Balakin et al. 1996), we assumed that structural probing of one of the new snoRNAs might facilitate identification of conserved structural elements common to this class of snoRNAs. An in vitro-transcribed U64 snoRNA labeled at the $5^{\prime}$ (Fig. $3 \mathrm{~A}$ ) or at the 3 ' (Fig. 3B) end was subjected to partial digestion with either single- (RNase $T_{1}$ and $A$, and nuclease $S 1$ ) or double-strand-specific $\left(R N a s e V_{1}\right)$ nucleases under nondenaturing conditions. A summary of the nuclease probing experiments and the deduced secondary structure of U64 is shown in Figure 3C. According to the proposed model, which is consistent with all nucleolytic cleavages, the human U64 snoRNA consists of two major hairpin domains connected by a single-stranded hinge
A

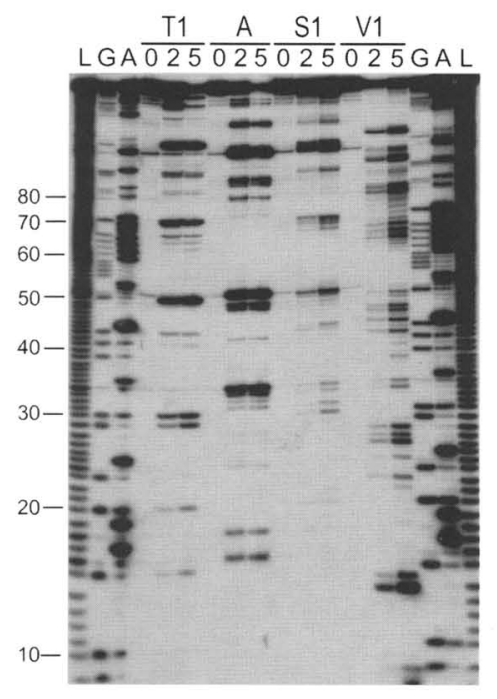

B

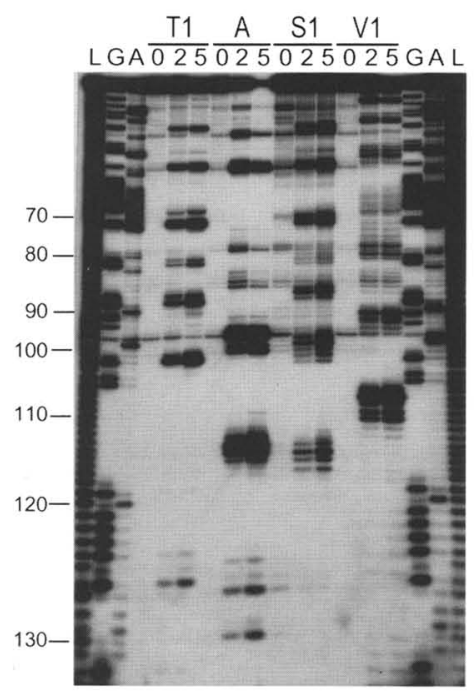

C

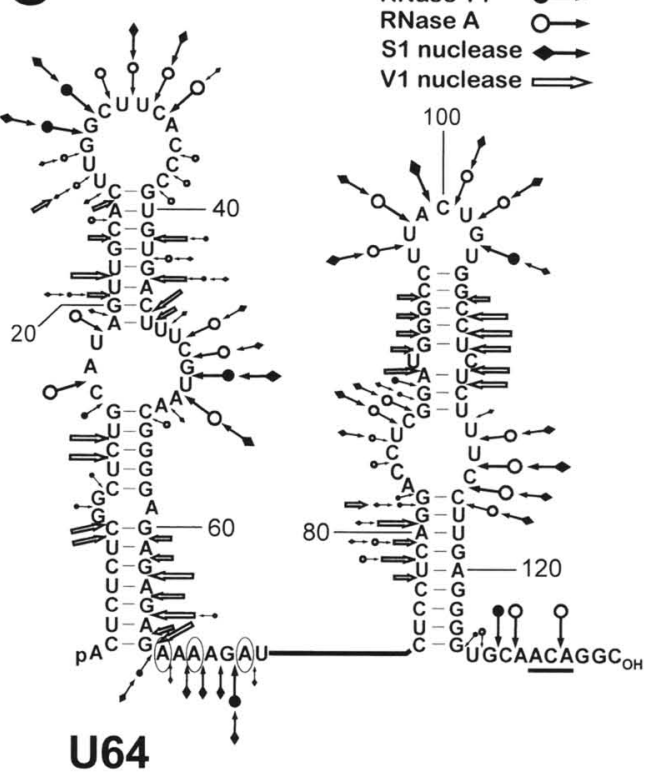

Figure 3. Secondary structure probing of human U64 snoRNA. $(A, B)$ Nuclease probing of in vitro-synthesized human U64 snoRNA transcripts labeled either at their $5^{\prime}(A)$ or $3^{\prime}(B)$ termini. Terminally labeled and purified RNA was subjected to partial digestion under nondenaturing conditions with RNase $\mathrm{T}_{1}(\mathrm{~T} 1)$, RNase $\mathrm{A}$ (A), nuclease $\mathrm{S} 1$ (S1), or RNase $\mathrm{V}_{1}$ (V1). Incubation times (in min) are indicated above the lanes. The RNA fragments were fractionated on $8 \%$ sequencing gels. (Lanes $\mathrm{G}, \mathrm{A}$ ) Guanosine- and adenosine-specific sequencing ladders generated by partial digestion under denaturing conditions with RNase $T_{1}$ and $U_{2}$, respectively; (lanes $L$ ) alkaline hydrolysis ladders. Numbering of nucleotides in the U64 snoRNA sequence is indicated. (C) A proposed secondary structure for human U64 snoRNA. Nucleotides cleaved by structure probing enzymes are indicated by nuclease-specific symbols. The sizes of the symbols refers to the observed intensity of the cleavage. The solid line connects contiguous sequences. The ACA box and the evolutionarily conserved A residues in the hinge region of U64 are underlined and circled, respectively. 
region. The 3' hairpin is followed by a short singlestranded tail that contains the conserved ACA motif.

\section{Box ACA snoRNAs share a phylogenetically conserved core structure}

Recently, we proposed a secondary structure model for another mammalian ACA snoRNA, U19 (Kiss et al. 1996). Now in the light of the results of U64 probing, it became apparent that a large domain of U19 RNA folds into a hairpin-hinge-hairpin-tail structure similar to that proposed for U64 (see Fig. 2, C and D, in Kiss et al. 1996). This observation suggested that the ACA snoRNAs might share common structural properties. We therefore performed a systematic computer-aided modeling of all known box ACA snoRNAs using the U64 structure as a guideline.

We found that the majority of mammalian ACA snoRNAs, including the newly identified U65-U72 and the previously characterized E2 and E3 snoRNAs (Ruff et al. 1993), can be folded into a U64-like secondary structure (Fig. 4A; data not shown). Moreover, computer-predicted structures of four Tetrahymena snoRNAs, which lack C and D boxes (Nielsen et al. 1992), but contain ACA or AUA boxes (P. Ganot et al., this paper), also conform to the structure of U64 (Fig. 4B). In these mammalian and ciliate snoRNAs, the $5^{\prime}$ and $3^{\prime}$ hairpin domains that contain one or occasionally two internal loops are connected with 6- to 15-nucleotide long, singlestranded, purine-rich hinge regions. The $5^{\prime}$ hairpin is preceded by one or two unpaired nucleotides. The length of the single-stranded $3^{\prime}$ tail that carries the ACA or AUA triplet varies from 6 to 10 nucleotides. The lack of a full-length ACA box in Tetrahymena snoRNA01 suggests that the reported sequence for this RNA is incomplete, as the presence of an intact ACA motif is essential for RNA accumulation both in yeast (Balakin et al. 1996) and mammalian cells (see below).

Extension of these investigations to yeast snoRNAs revealed that large domains of many yeast ACA snoRNAs (snR3， snR5， snR8， snR9， snR10， snR32， snR33, snR35, snR43, snR44, and snR189) can be folded into a hairpin-hinge-hairpin-tail structure highly reminiscent of mammalian and ciliate ACA snoRNAs. As a representative example, snR3 is shown in Figure 4C. (Foldings of other yeast snoRNAs are available upon request.) As compared to vertebrate and ciliate ACA snoRNAs, the hairpin domains of yeast snoRNAs are longer and frequently contain two or more internal loops and bulge loops. The trimethylguanosine-capped yeast ACA snoRNAs always carry 10- to 50-nucleotide-long, loosely structured leader sequences preceding the $5^{\prime}$ hairpin domain (Fig. 4C) (Balakin et al. 1996).

In many yeast snoRNAs, the hairpin-hinge-hairpintail core domain is extended with one or two additional stem-loop structures, referred to as inserted hairpin elements $(I H)$. These $I H$ elements are positioned either at the top of the upstream helix segment immediately preceding the hinge region $(I H 1)$ or at the $3^{\prime}$ end of the hinge region preceding the $3^{\prime}$-terminal hairpin (IH2). The first group comprises snR36 (Fig. 4C), snR31, snR32, and snR34, whereas snR11, snR30, snR37, and snR46 constitute the second group. One RNA, snR42, contains both types of inserted hairpin elements (Fig. 4C). Apparently, these extended secondary structures are not confined to yeast ACA snoRNAs, as mammalian U19 snoRNA carries an IH2-type element (Kiss et al. 1996), and an evolutionarily conserved secondary structure proposed for vertebrate U17 snoRNA (Cecconi et al. 1994, 1996) features both $I H 1$ and $I H 2$ elements.

In summary, we propose that eukaryotic ACA snoRNAs share a common structural domain that consists of two hairpin elements connected with a singlestranded purine-rich hinge region and followed by a short tail sequence encompassing the ACA consensus triplet. In some snoRNAs, the core structure is extended by one or two additional hairpin elements (IH1 and IH2), whose positions are conserved during evolution.

Elements required for processing and accumulation of ACA snoRNAs are evolutionarily conserved

It has been demonstrated that the coding regions of U17 and U19 snoRNAs contain all the structural elements that are necessary for correct processing of these intronencoded snoRNAs (Kiss and Filipowicz 1995; Kiss et al. 1996). We tested whether the simple hairpin-hinge-hairpin-tail structure of the novel snoRNAs accommodates all the elements required for processing (Fig. 5A). The coding regions of U64, U65, and U66 RNAs were inserted into the second intron of the human $\beta$-globin gene that was placed under the control of the cytomegalovirus (CMV) promoter (Kiss and Filipowicz 1995). Upon transfection of the resulting constructs into simian COS cells, accumulation of mature snoRNAs and globin mRNA was assayed by RNase mapping using probes specific for each pre-mRNA. The U64, U65, and U66 snoRNAs were processed efficiently and, as demonstrated by control mappings with human snoRNAs, correctly from the $\beta$-globin pre-mRNA (cf. lanes 2 and 4, lanes 6 and 8, lanes 10 and 12).

Yeast snR36 is likely processed from a longer precursor RNA, as it is devoid of a trimethylguanosine cap (Samarsky et al. 1995), and apart from an extra AU-rich hairpin structure $\{I H 1$ element\}, it folds into a secondary structure similar to that predicted for many human intron-encoded ACA snoRNAs (Fig. 4C). We tested the processing of yeast snR36 from the human $\beta$-globin premRNA in mammalian cells. Mapping of RNA isolated from transfected COS cells revealed that snR36 was processed efficiently from the globin pre-mRNA, yielding an RNA identical in size to the authentic yeast snR36 (Fig 5A, cf. lanes 14 and 16). This supports the assumption that snR 36 is generated by RNA processing in yeast and, more importantly, demonstrates that the structural elements required for processing and accumulation of ACA snoRNAs are evolutionarily conserved between human and yeast.

The ACA box of yeast snoRNAs plays an essential role in RNA accumulation (Balakin et al. 1996). It has been postulated to direct the binding of specific proteins that 


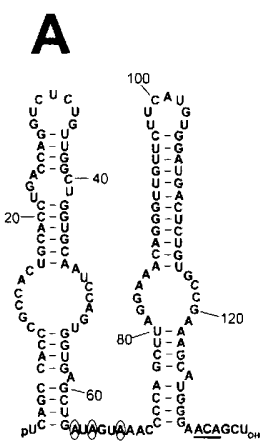

U65

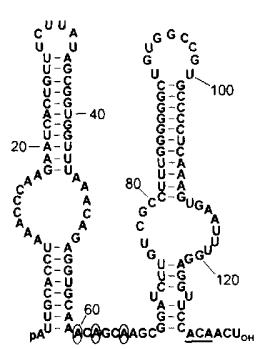

$\mathrm{U} 68$

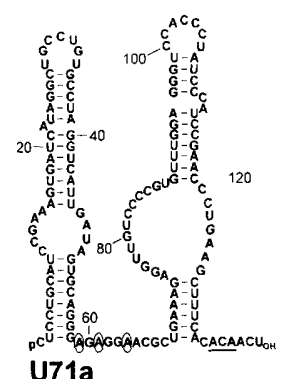

B

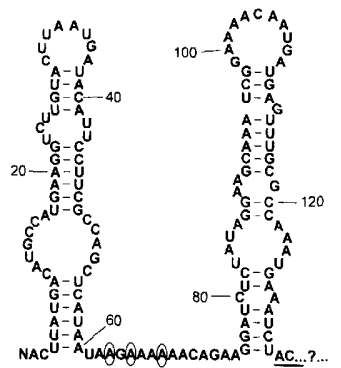

SnORNA01

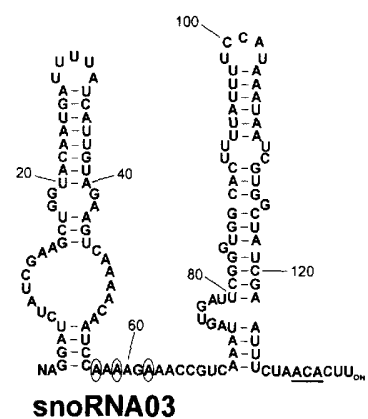

SnORNA03

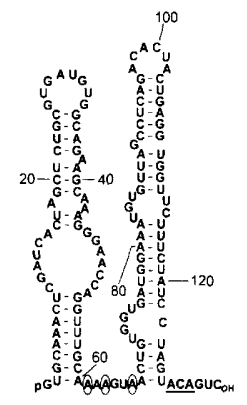

U66

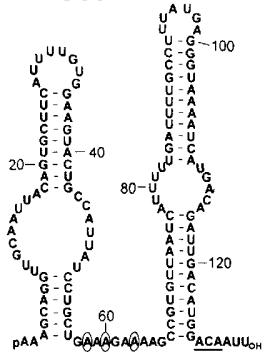

U69

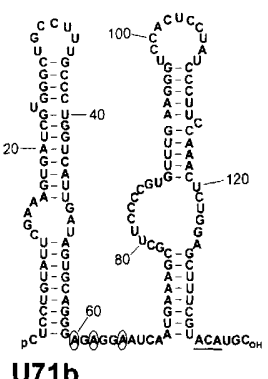

U71b

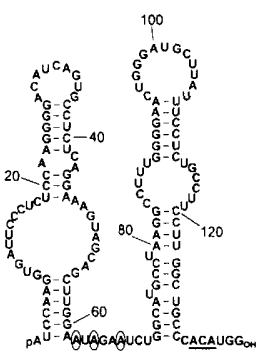

U67

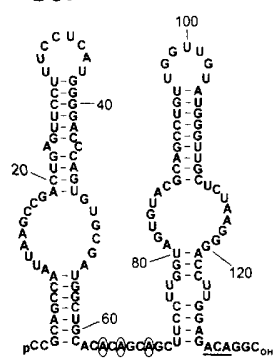

U70

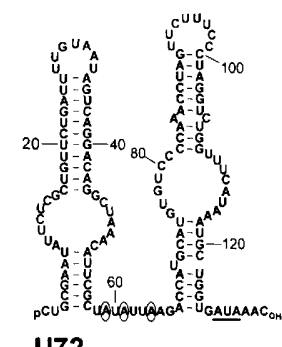

U72

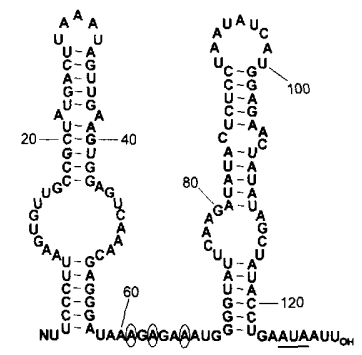

snoRNA02

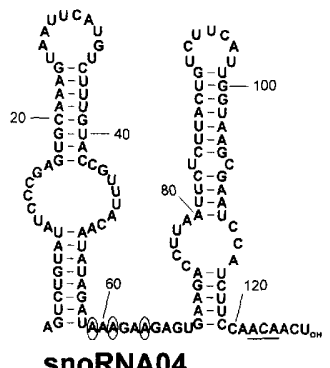

SnORNA04

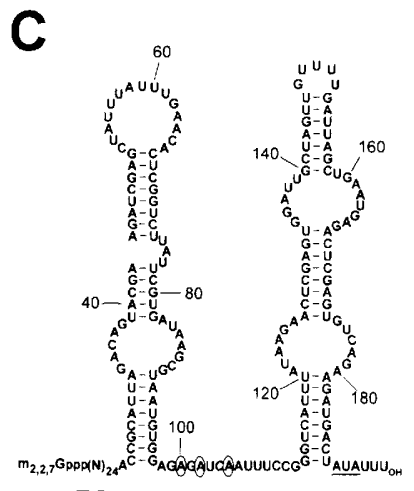

snR3
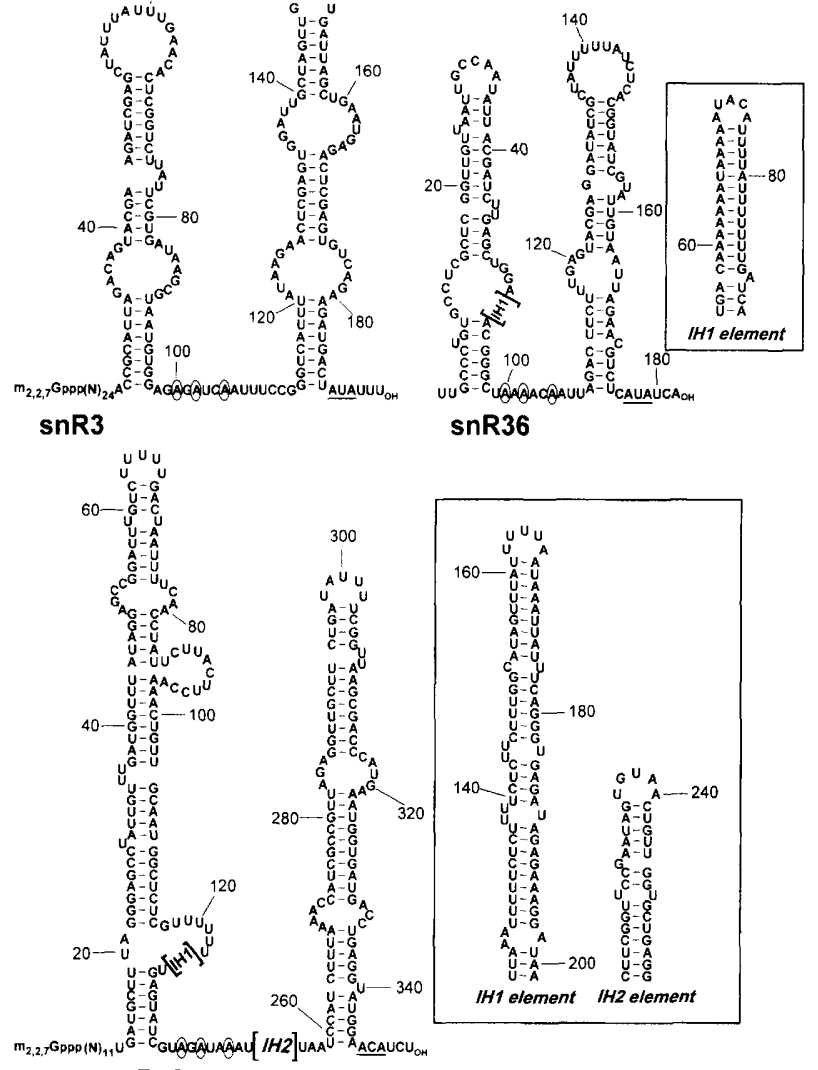

snR42

Figure 4. Computer-generated secondary structure of ACA box-containing snoRNAs. $(A)$ Predicted secondary structures of the newly identified human snoRNAs. $(B)$ Proposed secondary structures for ACA snoRNAs isolated from Tetrahymena thermophila (Nielsen et al. 1992). (C) Proposed structural models for representative examples of yeast Saccharomyces cerevisiae box ACA snoRNAs. The sequences of yeast snoRNAs were obtained from the database. (For GenBank accession numbers, see Balakin et al. 1996.| The ACA motifs and the evolutionarily conserved A residues in the hinge regions of snoRNAs are underlined or circled, respectively. 
A
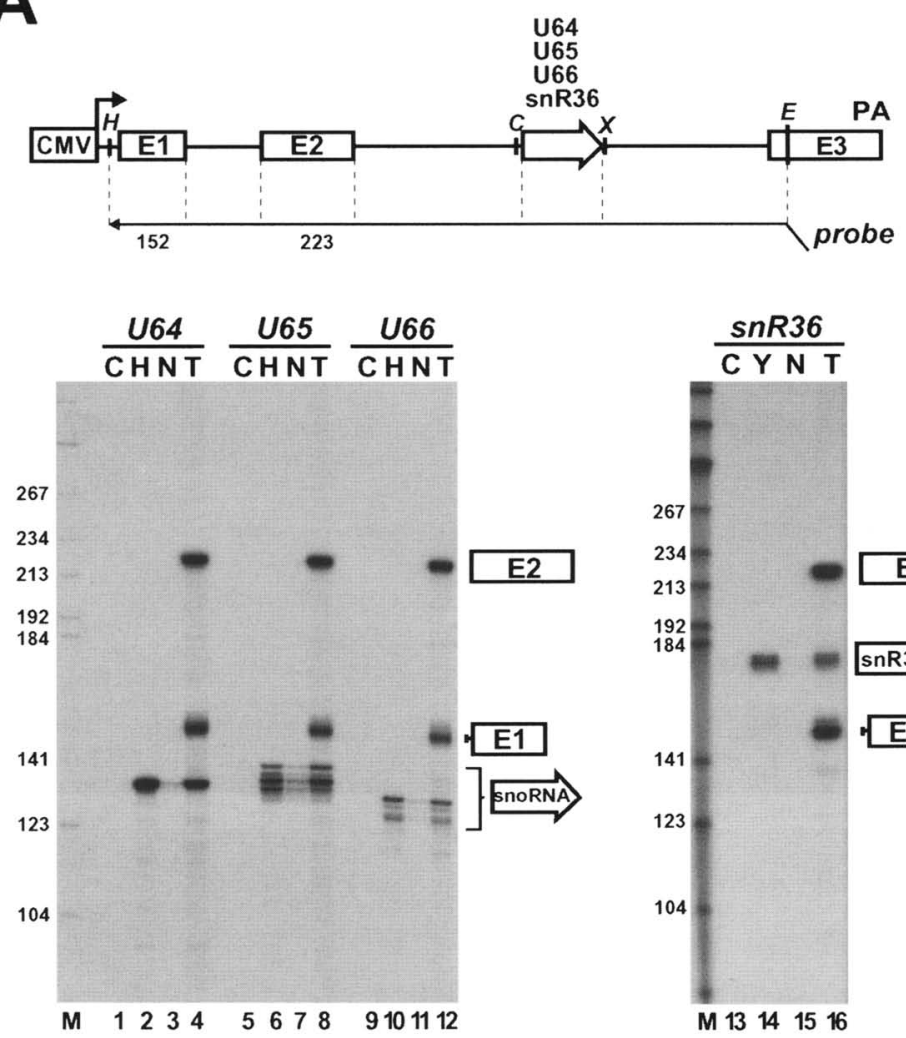

B

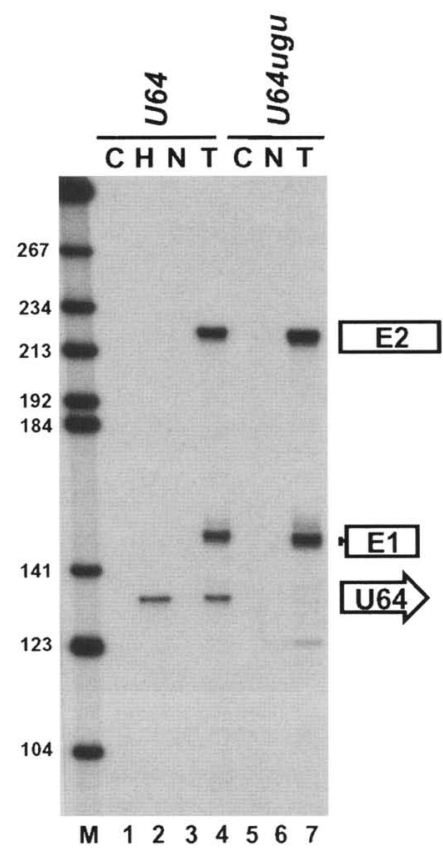

Figure 5. Elements required for processing of box ACA snoRNAs are evolutionarily conserved. (A) Processing of human U64, U65, U66, and yeast snR36 snoRNAs from the human $\beta$-globin pre-mRNA expressed in simian COS cells. A schematic structure of the expression constructs is shown at the top. The CMV promoter, the exon regions of the globin gene (E1-E3), the polyadenylation site $(\mathrm{PA})$, and the relevant restriction sites $\left[(C) C l a I_{;}(H)\right.$ HindIII; $(E) E C O R I ;(X)$ XhoI] are indicated. The open arrow indicates either human U64, U65, U66 or yeast snR36 snoRNA inserted into the second intron of the globin gene. RNA probes and expected lengths of the protected exons are shown below. The probes and RNA samples used for RNase $A / T_{1}$ protection are indicated above the gel lanes. (Lanes C) E. coli tRNA; (lanes H) HeLa cellular RNA; (lane Y) yeast cellular RNA; (lanes N) RNA from mock-transfected COS cells; (lanes T) RNA from COS cells transfected with the appropriate expression construct. Positions and structures of the protected fragments are indicated. Note that the appearance of several U65- and U66-specific protected bands is an artifact of RNase A/ $\mathrm{T}_{1}$ mapping, as no sequence or size heterogeneity was observed for these RNAs in HeLa cells (data not shown). (Lanes M) Size markers. (B) Processing of human U64 snoRNA carrying the wild-type (U64) or a mutant box ACA element (U64ugu) from the second intron of the human $\beta$-globin pre-mRNA expressed in COS cells (for details, see the legend to $A$ ).

could define the $3^{\prime}$ boundary of the snoRNA by protecting the coding sequences from exonuclease activities responsible for the 3 '-end formation of ACA snoRNAs. To determine whether the ACA box of mammalian snoRNAs is of similar functional importance, expression of a mutant U64 snoRNA carrying a mutant ACA box (U64ugu) was investigated (Fig. 5B). As expected, alteration of the ACA box of U64 completely abolished the accumulation of mature U64 snoRNA, demonstrating that the presence of an intact ACA box is essential for accumulation of mammalian ACA snoRNAs as well.

\section{A novel box element required for accumulation of human U64 snoRNA}

In the course of structural modeling of box ACA snoRNAs, we noted that sequences positioned in the single-stranded hinge region of ACA snoRNAs are enriched in purine, especially adenosine residues. Comparison of the hinge sequences of 37 different ACA snoRNAs obtained from phylogenetically distant species revealed a conserved sequence motif with a consensus AnAnnA (Fig. 6). The underlined A residues are perfectly conserved in all known box ACA snoRNAs. In the last position of the consensus sequence, human U23, mouse $\mathrm{U} 65$, yeast $s n R 9$, snR32, and $s n R 33$ possess a $\mathrm{G}$ residue and in one RNA, yeast snR44, A6 is replaced by a $U$ residue. We designated the novel motif the box $\mathrm{H}$ element, after its location in the hinge region of ACA snoRNAs. In most cases, the $\mathrm{H}$ box follows immediately the upstream helix segment or it is preceded by one to three unpaired spacer nucleotides. The single-stranded nature of the $\mathrm{H}$ box strongly suggests that it functions as a protein-binding signal, thereby playing an essential role in accumulation, processing, or function of this class of snoRNAs. 
Figure 6. Compilation of the single-stranded hinge sequences of box ACA snoRNAs. The evolutionarily conserved A residues are underlined. Numbers indicate positions of the first nucleotides shown. Question marks indicate that the numbering of these RNAs is tentative. Sequences of human (Kiss and Filipowicz 1993; Ruff et al. 1993|, Xenopus laevis (Cecconi et al. 1994), and Fugu rubripes (Cecconi et al. 1996) U17; human and mouse U19 (Kiss et al. 1996); and human E2 and E3 (Ruff et al. 1993; Séraphin 1993) snoRNAs have been published. Human U23 (L.-H. Qu, P. Ganot, and J.-P. Bachellerie, unpubl.) and chicken U72 snoRNAs (P. Ganot and T. Kiss, unpubl.) have been characterized recently. Mouse U65 and U72 snoRNAs were detected by database searches (GenBank accession nos. W11918 and K02928). Sequences of Tetrahymena snoRNAs have been reported by Nielsen et al. (1992). Sequences of yeast snoRNAs have been retrieved from the GenBank database (for accession numbers, see Balakin et al. 1996).

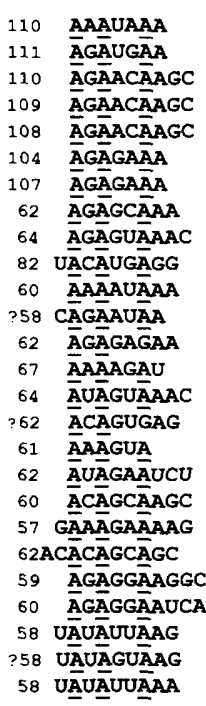

Saccharomyces cerevisiae:

\begin{tabular}{|c|c|c|}
\hline SnR3 & 98 & AGAGAUCA-AUUUCCG \\
\hline snR5 & 88 & UÁGACCA-A $(U)_{8}$ \\
\hline snR8 & 77 & UAGAGCAACUCCCACA \\
\hline snR9 & 81 & AUCA-AAUAGACCAAUUA \\
\hline SnR10 & 125 & UGGÄGÄACAAAU \\
\hline snR11 & 159 & UCUÄGAUUAAAUAUA \\
\hline snR189 & 86 & GA-GAAUAAGUACAAAU \\
\hline SnR30 & 390 & AGGAUUUA- \\
\hline SnR31 & 107 & ĀGĀUUA-AUUA \\
\hline snR32 & 109 & UÄGĀUAGAUU \\
\hline $\operatorname{snR} 33$ & 98 & GÄGAUUUGA \\
\hline $\operatorname{snR} 34$ & 111 & CA-GA-AUAAUUUAUUUU \\
\hline $\operatorname{snR} 35$ & 95 & GA-GAUCAUCA \\
\hline $\operatorname{snR} 36 *$ & 99 & UAAAAACAAUU \\
\hline snR37 & 170 & AAAUCAU \\
\hline nR42 & 210 & GUAGA-UAAAU \\
\hline 2R43* & 63 & AAGAUCA- \\
\hline $2 R 44$ * & 115 & A-UAUUUUAAUCCC \\
\hline nR4 6* & 67 & UAAAUUAACGAUC \\
\hline
\end{tabular}

Tetrahymena thermophila:

\begin{tabular}{|c|c|c|}
\hline A01 & 61 & UAAGAAAAAACAGAA \\
\hline $\mathrm{A} 02$ & 58 & 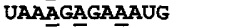 \\
\hline sn & 57 & 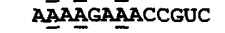 \\
\hline snORNAO & 59 & AAAGAAGAGU \\
\hline
\end{tabular}

To test this assumption, we conducted a mutational analysis of the box $\mathrm{H}$ element of human U64 snoRNA. Human $\beta$-globin pre-mRNAs carrying mutant U64 snoRNAs were expressed in simian COS cells. Accumulation of the processed snoRNA and the spliced globin mRNA was monitored by RNase mapping (Fig. 7). When the wild-type sequence of the $H$ box (AaAagA) was replaced with oligonucleotide $\mathrm{G}$ (U64Hgggggg), accumulation of U64 was completely abolished (lane 7), demonstrating that the $\mathrm{H}$ box is absolutely required for RNA accumulation. Another conclusion drawn from this experiment is that although the $\mathrm{H}$ boxes are generally en- riched in purine residues, a tract of $G$ residues cannot support accumulation of U64.

We attempted to rescue the expression of U64 $\mathrm{Hg} g g g g$ by substitution of the G1, G3 and G6 residues for A residues. Consistent with expectations, restoration of the consensus box $\mathrm{H}$ sequence in $\mathrm{U} 64 \mathrm{HAgAgg} A$ rescued the accumulation of U64 snoRNA (cf. lanes 3 and 5), whereas replacement of only the Gl residue by an $A$ in U64HAggggg failed to restore RNA accumulation (lane 9). In contrast, we observed a high level of accumulation for U64HAgAggg (lane 11). This observation justifies the naturally occurring $\mathrm{G} 6$ residue in the $\mathrm{H}$ boxes of few
Figure 7. Expression of human U64 snoRNA with altered nucleotides in box $\mathrm{H}$. Accumulation of U64 snoRNAs possessing wild-type (U64) or mutant box $\mathrm{H}$ sequences $(\mathrm{U} 64 \mathrm{H}$ followed by altered nucleotides in positions 62-69). RNAs isolated from nontransfected $(\mathrm{N})$ or transfected $(\mathrm{T})$ COS cells were mapped with sequencespecific RNA probes as indicated above the lanes. (For other details, see the legend to Fig. 5.)

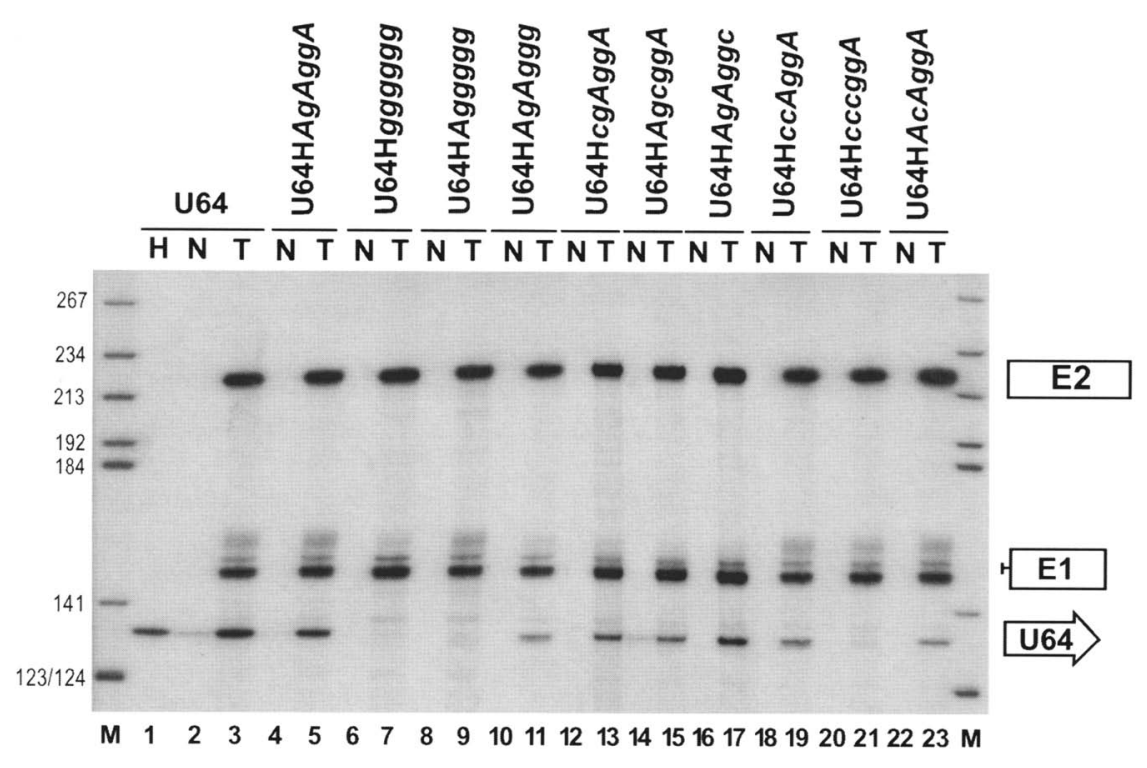


snoRNAs (see above). To our surprise, no major effect was observed when either $\mathrm{A} 1, \mathrm{~A} 3$, or $\mathrm{A} 6$ of the $\mathrm{H}$ box of $\mathrm{U} 64 \mathrm{H} A g A g g A$ had been replaced by a $\mathrm{C}$ residue. The resulting $\mathrm{U} 64 \mathrm{H} c g A g g A$, U64HAgcggA, and $\mathrm{U} 64 \mathrm{H} A g A g g c$ RNAs accumulated efficiently (lanes 13, 15, and 17). Consistent with this observation, the nonfunctional box $\mathrm{H}$ element of $\mathrm{U} 64 \mathrm{H} \operatorname{ccgg} A$ (lane 21) was rescued by replacement of $\mathrm{C} 3$ with an $\mathrm{A}$ residue. The resulting U64HccAggA RNA accumulated to the level of the control U64HAcAggA RNA, which carries a consensus $\mathrm{H}$ box (cf. lanes 19 and 23). These results show that two correctly placed $\mathrm{A}$ residues in the box $\mathrm{H}$ motif can already constitute an active molecular signal supporting the processing and accumulation of these snoRNAs.

In summary, our results demonstrate that the box $\mathrm{H}$ element represents a novel evolutionarily conserved sequence motif that plays a fundamental role in the accumulation of human U64 snoRNA. The H box likely represents a protein recognition signal that functions in concert with other structural elements (see Discussion).

\section{Yeast ACA snoRNAs are complexed with GAR1 but} not with fibrillarin

Yeast ACA snoRNAs have been reported to be associated with two essential nucleolar proteins, GAR1 and fibril- larin (NOP1) (Balakin et al. 1996). Whereas GAR1 seems to be specific for box ACA snoRNAs, NOP1 was reported to be complexed with all yeast snoRNAs but 7-2/MRP RNA. We reinvestigated the association of NOP1 and GAR1 proteins with yeast nucleolar RNAs. To avoid potential nonspecific reactions of anti-GARl or anti-NOP1 antibodies with other nucleolar proteins (Schimmang et al. 1989; Tollervey et al. 1991), we used yeast strains expressing epitope-tagged versions of GAR1 or NOP1. Two copies of the immunoglobulin G (IgG)-binding domain of Staphylococcus aureus protein A (Nilsson et al. 1987) were fused to the carboxy- or amino-terminal domains of GAR1 and NOP1 proteins, respectively. Because the GAR1-ProtA and ProtA-NOP1 fusion proteins supported cell growth at wild-type levels (data not shown), we concluded that they are fully functional. As a control, a yeast strain expressing a protein A-tagged nuclear pore protein, NSP1 (Grandi et al. 1993), was used. Cell extracts were prepared from each strain, and snoRNAs associated with the tagged proteins were immunoprecipitated with IgG-Sepharose.

Analysis of the immunoprecipitated RNAs by $3^{\prime}$ endlabeling followed by size fractionation on a denaturing polyacrylamide gel showed that two distinct classes of snoRNAs were retrieved from extracts obtained from the GAR1-ProtA or ProtA-NOP1 yeast strains (Fig. 8A).

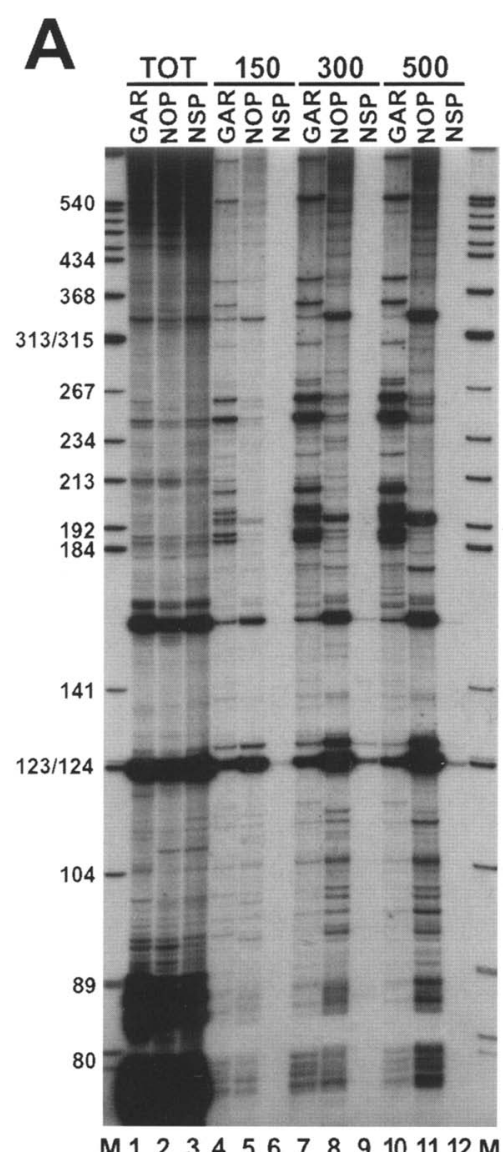

$M 123456789101112 M$

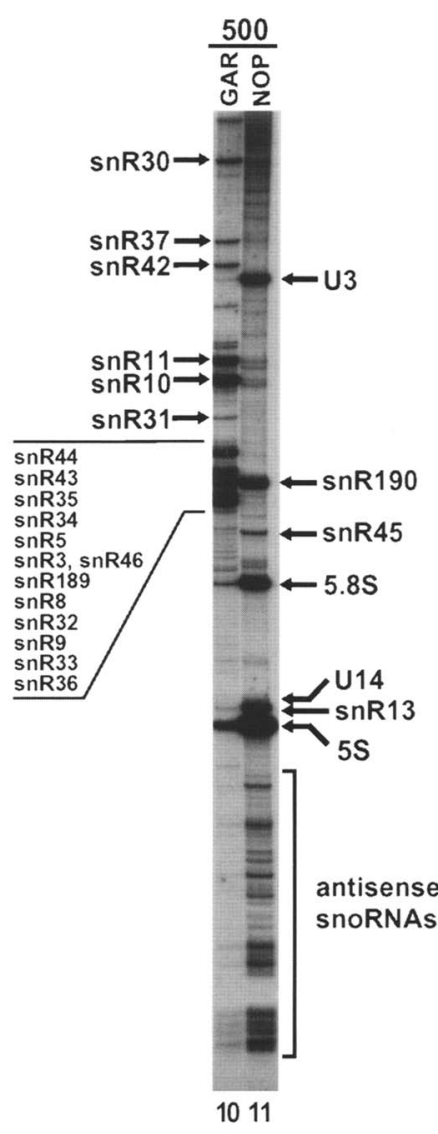

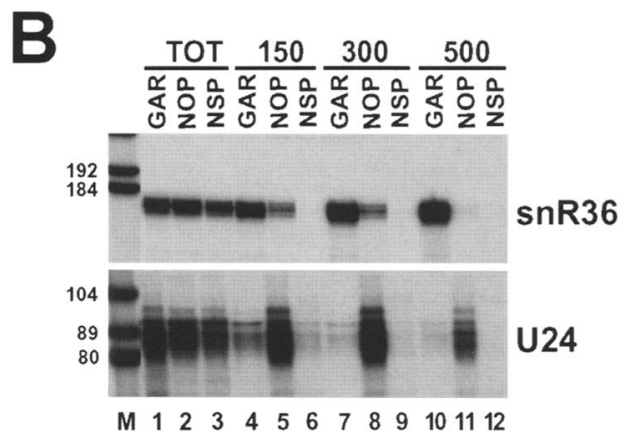

Figure 8. Yeast snoRNAs associated with nucleolar GARl or fibrillarin (NOPl) proteins. (A) Patterns of 3 ' end-labeled snoRNAs immunoprecipitated from yeast extracts. Cellular extracts prepared from yeast strains expressing either GAR1ProtA (GAR), ProtA-NOP1 (NOP), or NSP1-ProtA (NSP) fusion proteins were incubated with IgGSepharose in the presence of 150,300 , or $500 \mathrm{mM}$ KAc. RNAs recovered from the cellular extracts (TOT) or from the pellets of immunoprecipitation reactions were radiolabeled at their $3^{\prime}$ ends with $5^{\prime}-\left[{ }^{32} \mathrm{P}\right] \mathrm{pCp}$ in the presence of T4 RNA ligase and fractionated on a $6 \%$ sequencing gel. Positions of the most evident box ACA snoRNAs (lane 10) and box C/D snoRNAs (lane 11) are indicated (Balakin et al. 1996). (B) RNase mapping of immunoprecipitated snoRNAs. RNAs recovered from the cellular extracts (TOT) or from the pellets of immunoprecipitation reactions were mapped with antisense RNA probes specific for yeast snR36 or U24 snoRNAs. (Lanes M) Size markers. 
This was the most apparent in immunoprecipitation reactions performed in the presence of $500 \mathrm{mM} \mathrm{KAc}$, where most of the snoRNAs were recovered with $>80 \%$ efficiency. Under these conditions, box ACA snoRNAs showed specific association with GAR1 (lane 10), whereas box C/D snoRNAs were found to be complexed with NOP1 (lane 11). RNase mappings with probes specific for snR36 (a box ACA snoRNA) or U24 (a box C/D snoRNA) supported this observation further (Fig. 8B). At $500 \mathrm{~mm}$ KAc, the snR36 coprecipitated with GAR1 (lane 10 ) and was not present among snoRNAs associated with NOP1 (lane 11), whereas U24 snoRNA was found exclusively in the immunoprecipitate obtained from the ProtA-NOP1 strain (lane 11).

In immunoprecipitations performed at 150 and 300 mM KAc, although the overall patterns of snoRNAs retrieved form the GAR1-ProtA or ProtA-NOP1 strains remained clearly distinct, some box C/D snoRNAs were detectable among GAR1-associated snoRNAs (e.g., U3, snR13, and U24) (Fig. 8, A, lane 4, and B, lane 4) and vice versa, some ACA snoRNAs were apparent amongst NOP1-associated snoRNAs (e.g., snR10, snR11, and snR36) (Fig. 8, A, lane 5, and B, lanes 5 and 8). The most likely explanation of this observation is that at low salt concentration, small fractions of both box ACA and C/D snoRNPs remain associated with common higher order nucleolar complexes. Therefore, the observed precipitation of box ACA snoRNAs from extracts prepared from the ProtA-NOP1 strain or retrieval of box C/D snoRNAs from the GAR1-ProtA strain is attributable to indirect interactions rather than direct association of these snoRNPs with fibrillarin or GARl proteins, respectively.

\section{Discussion}

The snoRNAs can be classified into two major families according to the presence of conserved sequence motifs. Most snoRNAs studied so far possess boxes $\mathrm{C}$ and $D$ (Maxwell and Fournier 1995). Another group of snoRNAs, including many yeast and a few vertebrate snoRNAs, is defined by a consensus ACA motif positioned 3 nucleotides from the $3^{\prime}$ terminus (Balakin et al. 1996). Although box C/D snoRNAs have been studied extensively by several laboratories (see introductory section), little is known about the structure and function of box ACA snoRNAs. In this work, structure probing of a novel human ACA snoRNA, followed by systematic modeling of all known ACA snoRNAs, revealed that this class of snoRNAs is defined by a phylogenetically conserved secondary structure and ubiquitous box elements essential for RNA accumulation.

The nucleolus of mammalian cells contains a complex population of ACA snoRNAs

Although $>20$ different box ACA snoRNAs have been identified in the yeast Saccharomyces cerevisiae to date, only four ACA snoRNAs have been reported from mammalian cells (Kiss and Filipowicz 1993; Ruff et al. 1993; Kiss et al. 1996). In this study characterization of a
cDNA library of human intronic snoRNAs identified nine novel ACA box-containing snoRNAs. This indicates that mammalian cells, similarly to yeast cells, contain a complex population of ACA snoRNAs. In our cDNA library, $\sim 20 \%$ of the snoRNA-specific recombinant clones represented box ACA snoRNAs (Kiss-László et al. 1996). However, in marked contrast to box C/D snoRNAs (Balakin et al. 1994), the ACA snoRNAs possess compact secondary structures that can seriously hamper the cDNA synthesis of these RNAs. Therefore, we believe that the molecular complexity of mammalian ACA snoRNAs is higher than the present data suggest. This is supported by the fact that none of the novel mammalian snoRNAs shows convincing sequence similarity to any yeast ACA snoRNA characterized thus far.

\section{Box ACA snoRNAs are defined by a common secondary structure}

In spite of the fact that box ACA snoRNAs vary in size over a fourfold range, from 130 to 600 nucleotides, these RNAs, or large domains of these RNAs, can be folded into a similar core structure. This consensus structure features two major hairpin domains that are connected by a short single-stranded hinge region and followed by a short $3^{\prime}$ tail. Mammalian and ciliate ACA snoRNAs exhibit remarkable conservation both in size and secondary structure (Fig. 4). These snoRNAs consist of 130-140 nucleotides, and their predicted secondary structures conform perfectly to the consensus hairpin-hinge-hairpin-tail core structure of ACA snoRNAs. In yeast ACA snoRNAs, which range in size from 180 to 600 nucleotides, the two hairpin domains are usually elongated and the consensus core structure is frequently supplemented with additional hairpin elements. The positions of these extra hairpin elements are conserved and they are present as well in two vertebrate snoRNAs, U17 and U19. The functional significance, if any, of these extension elements is unclear. Processing studies on human U64, U65, and U66 snoRNAs demonstrated that the hairpinhinge-hairpin-tail core structure of these intronic RNAs accommodates all of the elements that are essential for RNA processing and accumulation (Fig. 5). The question remains whether the intriguing differences in overall length of animal and yeast ACA snoRNAs reflect fundamental differences in the function of these snoRNAs. However, according to an alternative and more plausible scenario, the increased length of yeast ACA snoRNAs reflects a general feature of yeast small nuclear RNAs (snRNAs), as has been observed for yeast spliceosomal snRNAs (Guthrie and Patterson 1988) and nucleolar U3 and U14 snoRNAs (Maxwell and Fournier 1995).

\section{The two major classes of snoRNAs show intriguing similarities}

In vertebrates, most box $C / D$ snoRNAs and all known box ACA snoRNAs are processed from introns of premRNAs. Accumulating evidence suggests that excision of intronic snoRNAs relies on exonucleolytic activities 
(Kiss and Filipowicz 1993, 1995; Xia et al. 1997). The C, $\mathrm{D}$, and ACA boxes of snoRNAs have been postulated to bind putative protein factor(s) which could delineate the terminal boundaries by protecting the snoRNAs from exonucleolytic degradation (Huang et al. 1992; Tycowski et al. 1993; Balakin et al. 1994, 1996; Caffarelli et al. 1996; Watkins et al. 1996; Xia et al. 1997).

The box ACA snoRNAs contain two evolutionarily conserved sequence motifs: the ACA box and the newly identified box $\mathrm{H}$ element. The $\mathrm{H}$ and ACA boxes are highly reminiscent of the extensively characterized $\mathrm{C}$ and $\mathrm{D}$ boxes. They are essential for RNA accumulation, and similarly to the C/D boxes, the H/ACA boxes always appear jointly. Inspection of a processing model proposed for intronic ACA snoRNAs allows further intriguing parallels to be drawn with box C/D snoRNAs (Fig. 9). The $\mathrm{H}$ and ACA boxes are contained within single-stranded regions that are in close proximity in the secondary structure of the snoRNA. The $\mathrm{H}$ and ACA boxes are brought together by a conserved helix structure (helix II). The importance of this helix in accumulation of a yeast ACA snoRNA, snR11, has been demonstrated (Balakin et al. 1996). Interestingly, many box C/D snoRNAs feature a stem structure similar to helix II (Tycowski et al. 1993; Watkins et al. 1996). Although this helix is dispensable for the accumulation of U14 snoRNA, it has been implicated in the processing of box C/D snoRNAs, which lack a $5^{\prime}, 3^{\prime}$ terminal stem structure (helix I) (Watkins et al. 1996).

In intron-encoded ACA snoRNAs, the box $\mathrm{H}$ motif directly follows the $5^{\prime}$ stem (helix I) or they are separated by one or two (U68) spacer nucleotides (Fig. 6). We noticed that snoRNAs lacking spacer nucleotides before the $\mathrm{H}$ box always possess one unpaired $5^{\prime}$ terminal

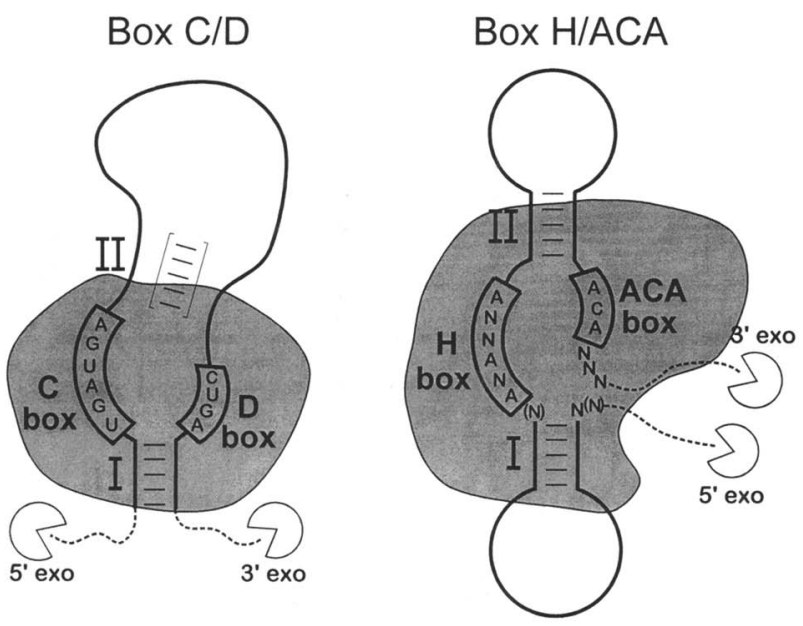

Figure 9. Comparison of processing models proposed for intron-encoded box C/D and box H/ACA snoRNAs. Solid lines indicate snoRNA sequences retained in mature snoRNAs. Intronic sequences destined for exonucleolytic degradation are indicated by broken lines. Putative snoRNP proteins that bind to large domains of the folded snoRNAs are represented by shaded overlays. (For other details, see text.) nucleotide, and snoRNAs carrying one or two spacer nucleotides invariantly feature two free $5^{\prime}$ terminal nucleotides of nonconserved sequence (Fig. 4A; data not shown). This strongly suggests that the box $\mathrm{H}$ element, probably in concert with the indispensable $5^{\prime}$-terminal stem (P. Ganot and T. Kiss, unpubl.), plays an essential role in delineation of the correct $5^{\prime}$ terminus of intronencoded ACA snoRNAs. Intriguingly, correct spacing (2 nucleotides) between the $\mathrm{C}$ box and the terminal stem (helix I) is fundamental for the processing of U14 box C/D snoRNA as well (Xia et al. 1997). In this context, it is noteworthy that replacement of the $\mathrm{Ul}$ residue for an A residue in the consensus sequence of the $\mathrm{C}$ box could, in principle, convert this element into a perfect $\mathrm{H}$ box motif.

Together, the $\mathrm{H}$ and ACA boxes, in concert with the neighboring $5^{\prime}$ and $3^{\prime}$ stem structures (helices I and II), are likely to be involved in the correct $5^{\prime}$ - and $3^{\prime}$-end formation of intronic ACA snoRNAs and are essential for RNA stability. The single-stranded nature of boxes $\mathrm{H}$ and ACA suggests that their function is mediated through interactions with specific RNA-binding proteins. We propose that the low information content of the box $\mathrm{H}$ and ACA motifs is compensated by the appropriate architecture of the helix I-box H-helix II-box ACA elements, which together constitute the docking site for specific snoRNP proteins. Interestingly, the molecular models suggested for the processing of box C/D and box H/ACA snoRNAs show intriguing structural and functional similarities. The box elements and helix structures exhibit similar sterical arrangements on the snoRNA secondary structures, and they possess similar functions. The resemblance between box $\mathrm{C} / \mathrm{D}$ and H/ACA snoRNAs shows that the common biosynthetic pathway of these snoRNAs relies on structurally and functionally similar cis-acting elements and inevitably raises the intriguing possibility that the two major classes of eukaryotic snoRNAs have evolved from a common ancestor molecule.

\section{Proteins associated with box $H / A C A$ and $C / D$} snoRNAs

We can envisage that snoRNAs defined by common sequence boxes share common associated proteins that are responsible for the specific recognition of the box elements. To date, no proteins have been implicated in direct binding to the $\mathrm{C} / \mathrm{D}$ or $\mathrm{H} / \mathrm{ACA}$ boxes, and only two proteins, fibrillarin and GAR1, have been demonstrated to associate with large subsets of snoRNAs (Maxwell and Fournier 1995; Balakin et al. 1996). Assembly of Xenopus U3 and U8 snoRNAs into fibrillarin-containing snoRNP particles requires intact $\mathrm{C}$ and $\mathrm{D}$ boxes (Baserga and Steitz 1991; Peculis and Steitz 1994) and consistent with this, all snoRNAs containing C/D boxes have been found to be complexed with fibrillarin (Maxwell and Fournier 1995; Kiss-László et al. 1996; Sollner-Webb et al. 1996). Unexpectedly, the yeast equivalent of fibrillarin (NOP1) has been reported to be complexed with almost all yeast snoRNAs, including box ACA snoRNAs 
(Schimmang et al. 1989; Balakin et al. 1996). In this work, using a yeast strain expressing a ProtA-NOP1 fusion protein, we demonstrated that NOP1 shows specific association with C/D box-containing snoRNAs and it is not complexed with box ACA snoRNAs or snoRNPs.

In yeast, the GARl protein, as demonstrated by immunoprecipitation studies with anti-GARl antibodies (Balakin et al. 1996) or by immunoselection of GAR1ProtA (this study), is specifically associated with the box H/ACA snoRNAs. The tight association of GAR1 with yeast snR30 (Lübben et al. 1995) suggests that GAR1 represents an integral part of the core structure of box ACA snoRNPs. No protein associated with mammalian ACA snoRNAs has been identified yet. However, the impressive structural relatedness of yeast and mammalian ACA snoRNAs and the correct processing of yeast snR36 RNA in mammalian cells strongly suggest that not only the cis-acting elements but also the trans-acting protein factors needed for processing and accumulation of box ACA snoRNAs are evolutionarily conserved. Therefore, we suggest that the two major classes of snoRNAs, the box C/D and box H/ACA snoRNAs, are defined universally by the associated fibrillarin or GAR 1 proteins, respectively.

\section{Are box ACA snoRNAs involved in pseudouridine formation?}

The notion that box ACA snoRNAs share a common secondary structure, conserved sequence motifs, and probably a set of common associated proteins argues that these RNAs possess common nucleolar function. In light of the recent demonstration that the majority of the fibrillarin-associated snoRNAs function as guide RNAs in site-specific ribose methylation of pre-rRNA (Kiss-László et al. 1996), it is logical to hypothesize that ACA snoRNAs, or a subset of these snoRNAs, may be involved in site-specific pseudouridine formation in prerRNA. As a first step toward testing this hypothesis, we have recently investigated the possible involvement of the yeast GARl protein in rRNA pseudouridine formation. We found that a thermosensitive mutation in the yeast GAR1 gene completely blocked the overall pseudouridylation of yeast pre-rRNA at the nonpermissive temperature. In contrast, $2^{\prime}$-O-ribose methylation of prerRNA and formation of pseudouridine residues on tRNAs were not affected under the same conditions (C. Bousquet-Antonelli, Y. Henry, J.-P. Gélugne, M. Caizergues-Ferrer, and T. Kiss, in prep.). This observation strongly supports an involvement of ACA snoRNAs in site-specific pseudouridylation of rRNAs, although at this moment we cannot rule out the possibility that the observed function of GAR1 in pseudouridine formation is independent of snoRNA association.

Formation of pseudouridine residues is an early event of rRNA maturation; it occurs shortly after synthesis but before processing of pre-rRNA (Jeanteur et al. 1968). Several lines of evidence indicate that ACA snoRNAs function in early steps of pre-rRNA processing. In this work we have shown that human U64, U65, and U66 ACA
snoRNAs are associated with $\sim 80$ S nucleolar complexes identical or similar to those known to contain primary rRNA transcripts, as well as U3 snoRNA that functions in an early step of pre-rRNA processing (Kass et al. 1990; Hughes and Ares 1991; Mougey et al. 1993). In another study three ACA snoRNAs, U17/E1, E2, and E3, have been cross-linked successfully to nucleolar pre-rRNA sequences (Rimoldi et al. 1993). The ACA snoRNAs, by analogy to the methylation guide snoRNAs, may select specific $U$ residues for pseudouridine formation through direct base-pairing interactions. Consistent with this, formation of pseudouridine residues in mammalian pre-rRNA depends on the specific nucleotide sequence surrounding the substrate $\mathrm{U}$ residue, rather than local secondary structures (M.-L. Bortolin and T. Kiss, unpubl.). However, in contrast to the methylation guide snoRNAs, the ACA snoRNAs contain no obvious complementarities to rRNA sequences carrying pseudouridine residues. It is also possible that the tertiary structure of ACA snoRNAs may constitute a recognition signal by bringing together short sequence elements that are located on different regions of these snoRNAs. We believe that the consensus structure defined for ACA snoRNAs in this study will be beneficial to future investigations attempting to define the nucleolar function of this group of snoRNAs.

\section{Materials and methods}

\section{General procedures}

Unless stated otherwise, all techniques used for manipulating DNA, RNA, and oligodeoxynucleotides were performed according to standard laboratory manuals (Sambrook et al. 1989). The identity of all constructions was verified by sequence analysis. The following oligodeoxynucleotides were used in this study: (1) GTAATACGACTCACTATAGGACTCTCTCGGCTCTGCATAG; (2) TTACTCGAGGCCTGTTGCACCCCTCAAGG; (3) TATATCGATACTCTCTCGGCTCTGCATAG; (4) TATATCGATTCAGCCACCCGCCACTGC; (5) TTCTCGAGCTGTTCCCATGCTTTCGG; (6) TTAATCGATGTGCAAACTCGATCACTAG; (7) TTACTCGAGACTGTACTAGGATAG; (8) TTTATCGATTGCCCTGTGCCTCGCTCGG; (9) TTACTCGAGTGATATGAGACGTTCTAATTA; (10) TTTCTCGAGGCCACATGCACCCCTCAAG; (11) CCCGGATCCTTCAGCATGCCTTGCGCAACAG; and (12) CCCGGATCCGGTACCGAGCTCGAATTCGCG.

\section{Identification and characterization of SnORNAs}

Construction of a cDNA library of human intron-encoded snoRNAs in the pBluescribe (Stratagene) vector and identification of novel snoRNAs by sequence analysis has been described (Kiss-László et al. 1996). Recombinant plasmids carrying fulllength cDNA copies of U64-U72 snoRNAs were called pU64pU72, respectively. Expression and primary structure of the novel snoRNAs was verified by Northern analysis and RNase $A / T_{1}$ mapping using sequence-specific RNA probes. The 5' ends of snoRNAs were verified by primer extension.

Secondary structure probing and computer folding of SnORNAs

The coding region of human U64 snoRNA was cloned behind the T7 RNA polymerase promoter by a PCR approach using 
pU64 as template. The $5^{\prime}$ primer (oligonucleotide 1) contained the sequence of the T7 RNA polymerase promoter followed by the $205^{\prime}$-terminal nucleotides of U64. The $3^{\prime}$-end-specific primer (oligonucleotide 2) contained a 20 -nucleotide long sequence complementary to the 3 '-terminal region of U64 followed by an $X$ hoI restriction site. The amplified fragment was cloned into the SmaI site of pSP64, linearized with XhoI, and used as a template for in vitro transcription of U64 snoRNA. The resulting U64 RNA transcript contained two additional G residues at the $5^{\prime}$ end and extra CUCGA sequences at the $3^{\prime}$ end. Structure probing of RNA was performed according to Krol and Carbon (1989). Secondary structure modeling of snoRNAs was performed by using the MFOLD program of Genetics Computer Group, Inc. (GCG). The RNA secondary structures were visualized and edited with the RNA d2 computer program described by Perochon-Dorisse et al. (1995).

\section{Cell fractionation and glycerol gradient analyses}

Isolation of nuclei from human HeLa cells, and subfractionation of nuclei into nucleolar and nucleoplasmic fractions were performed as described by Tyc and Steitz (1989) and Kiss et al. (1992). Sonicates prepared from $5 \times 10^{6} \mathrm{HeLa}$ cells were loaded on a $10 \%-30 \%$ glycerol gradient and sedimented at $25,000 \mathrm{rpm}$ for $10 \mathrm{hr}$ at $4^{\circ} \mathrm{C}$ in a SW41 rotor (Beckman) as described by Tyc and Steitz (1989). The gradients were fractionated into 22 samples, and RNA recovered from each fraction was analyzed by RNase $A / T_{1}$ mapping.

\section{Isolation of RNA}

RNAs from HeLa cells, transfected COS cells, and yeast cells were isolated by guanidinium thiocyanate/phenol-chloroform extraction as described by Goodall et al. (1990) and Tollervey and Mattaj (1987), respectively. The hot phenol/SDS method (Steele et al. 1965) was used for isolation of RNA from subcellular fractions of HeLa cells, yeast cell extracts, and pellets of immunoprecipitation reactions. RNA from glycerol gradient fractions was recovered by proteinase $\mathrm{K}$ treatment in the presence of $0.5 \%$ SDS at $55^{\circ} \mathrm{C}$, followed by phenol-chloroform extraction.

\section{Construction of plasmids for transfection of COS-7 cells}

Construction of the mammalian expression vector, $\mathrm{pG}_{\mathrm{CXM}}$, was described earlier (Kiss and Filipowicz 1995). Briefly, the human $\beta$-globin gene containing three newly introduced restriction sites (ClaI, XhoI, and MluI) in the second intron was placed under the control of the CMV promoter. To obtain $\mathrm{pG} / \mathrm{U} 64$, $\mathrm{pG} / \mathrm{U} 65, \mathrm{pG} / \mathrm{U} 66$, and $\mathrm{pG} / \mathrm{snR} 36$, the coding regions of human U64, U65, and U66, and yeast snR36 RNAs were PCR amplified with $5^{\prime}$ - and $3^{\prime}$-end-specific primers (oligonucleotides $3 / 2,4 / 5$, $6 / 7$, and $8 / 9$, respectively). Use of these primers resulted in inclusion of $\mathrm{ClaI}$ and XhoI sites adjacent to the $5^{\prime}$ and $3^{\prime}$ termini, respectively, of the snoRNA-coding regions. The amplified fragments were cut by $C l a \mathrm{I}$ and $X h o \mathrm{I}$ and inserted between the ClaI and XhoI sites of $\mathrm{pG}_{\mathrm{CXM}}$. pG/U64ugu was constructed like $\mathrm{pG} / \mathrm{U} 64$, except that the $3^{\prime}$-end-specific primer (oligonucleotide 10/ contained appropriate base changes to replace the wild-type ACA box of U64 for UGU.

Construction of a series of $\mathrm{pG} / \mathrm{U} 64 \mathrm{H}$ expression constructs carrying altered box $\mathrm{H}$ sequences was performed by the megaprimer amplification approach using pU64 as a template (Datta 1995). The $5^{\prime}$ half of mutant U64 snoRNAs was amplified using antisense oligonucleotides GGTCCTGAGGAGA(N) 6 CTCTCTCTCCCC carrying the appropriate mutagenic sequence $\left(\mathrm{N}_{6}\right)$ and a common primer complementary to the $5^{\prime}$ end of U64 (oligonucleotide 3 ). The resulting products were used as megaprimers in the second amplification step in combination with a common 3 '-end-specific primer (oligonucleotide 2). The amplified products were cut with ClaI and XhoI and cloned into the same sites of $\mathrm{pG}_{\mathrm{CXM}}$. Transfection of simian COS-7 cells was performed as described earlier (Kiss and Filipowicz 1995).

\section{RNase $A / T_{1}$ mapping}

RNase protection was performed as described by Goodall et al. (1990). RNA probes were synthesized in vitro with T3 or T7 RNA polymerase, using $\left[\alpha-{ }^{32} \mathrm{P}\right] \mathrm{CTP}(30 \mathrm{Ci} / \mathrm{mmole})$ and linearized plasmids as templates. All probes were purified on $6 \%$ denaturing polyacrylamide gels. RNA probes used for mapping human U3, U4, and U19 snoRNAs have been described (Kiss et al. 1992, 1996). To prepare RNA probes specific for U64-U72 snoRNAs, HindIII-linearized pU64-pU72 plasmids were used as templates for transcription by T7 RNA polymerase. To generate a probe for yeast snR36, the ClaI-XhoI fragment of $\mathrm{pG} / \mathrm{snR} 36$ containing the coding region of snR36 was cloned into the ClaIXhoI sites of pBluescript II, and the SacI-linearized recombinant plasmid was transcribed by T3 RNA polymerase. To obtain sequence-specific probes for human globin pre-mRNAs carrying U64, U65, U66, snR36, or mutant versions of U64 (U64ugu, U64H constructs), the HindIII-EcoRI fragment of pG/U64, pG/ $\mathrm{U} 65, \mathrm{pG} / \mathrm{U} 66, \mathrm{pG} / \mathrm{snR} 36$, and $\mathrm{pG} / \mathrm{U} 64 \mathrm{H}$ series of constructs was subcloned into the HindIII-EcoRI sites of pBluescribe. Probes were synthesized by T7 RNA polymerase from HindIIIlinearized recombinant plasmids.

\section{Immunoprecipitation}

Yeast strains expressing NSP1 (Grandi et al. 1993) or NOP1 (T. Berges, unpubl.| proteins tagged with two copies of the IgGbinding epitope of $S$. aureus protein A were kindly provided by Dr. E.C. Hurt (University of Heidelberg, Germany) and T. Berges (University of Poitiers, France), respectively. Epitope tagging of yeast GAR 1 protein was performed as follows. A DNA fragment encoding two synthetic IgG-binding domains of protein A (Nilsson et al. 1987) was PCR-amplified using sequence-specific primers (oligonucleotides 11 and 12) that introduced BamHI restriction sites at both the $5^{\prime}$ and $3^{\prime}$ termini. The amplified fragment was cut by $\mathrm{BamHI}$ and inserted into the $\mathrm{BamHI}$ site of pJPG67 (Girard et al. 1994). In the resulting expression construct, called pMCGZZ1, the GAR1-ProtA fusion gene was flanked by the authentic GAR1 promoter and terminator sequences. The derived amino acid sequence of the GAR1-ProtA fusion protein around the fusion sites was GAR1 amino-terminal residues (Met-1-Gly-5), linker sequence (Asp-Pro-Arg-PheGly), GAR1 (Gly-6-Arg-205), two IgG-binding units, and linker sequence (Asp-Pro-Asn-Leu-Ala-Arg-Lys-Lys). The GAL::gar1 yeast strain (Girard et al. 1992) was transformed with pMCGZZ1. Following transfer to glucose medium, the transformant yeast cells showed no deviation in growth rate in comparison to the wild-type strain, demonstrating that the plasmid-encoded GAR1-ProtA fusion protein is able to complement the otherwise lethal gar $^{-}$mutant.

Yeast cells corresponding to $50 \mathrm{OD}_{600}$ units of an exponentially growing culture were harvested, washed, and resuspended in $0.5 \mathrm{ml}$ of lysis buffer containing $20 \mathrm{mM}$ Tris- $\mathrm{HCl}(\mathrm{pH} 8), 5 \mathrm{~mm}$ $\mathrm{MgCl}_{2}, 150 \mathrm{~mm} \mathrm{KAc}, 1 \mathrm{~mm} \mathrm{DTT}$, and $0.2 \%$ Triton X-100 supplemented with protease inhibitor Complete (Boehringer) according to the manufacturer's recommendation. Cells were lysed by vigorous vortexing with $1.5 \mathrm{ml}$ of glass beads $(0.45-0.5$ $\mathrm{mm}$ ) for $5 \mathrm{~min}$. The lysate and $0.5 \mathrm{ml}$ of lysis buffer used to 
wash the glass beads were combined and cleared by centrifugation. About $300 \mu$ l of lysate, containing either $150 \mathrm{~mm}, 300 \mathrm{mM}$, or $500 \mathrm{~mm}$ of KAc, and $40 \mu \mathrm{l}$ of $50 \%$ IgG Sepharose (Pharmacia) in lysis buffer were incubated for $1 \mathrm{hr}$ on a rocking table. The beads were washed five times with $1 \mathrm{ml}$ of lysis buffer containing the appropriate concentration of KAc. Preparation of cell extracts and immunoprecipitation of snoRNPs were done at $4^{\circ} \mathrm{C}$.

\section{Acknowledgments}

We thank E.C. Hurt and T. Berges for providing yeast strains. We are grateful to $\mathrm{Z}$. Kiss-László for characterization of the cDNA library of human intronic snoRNAs, to C. BousquetAntonelli for the construction of GAR1-ProtA fusion gene, and to Yvette de Preval for synthesis of oligonucleotides. We also thank Y. Henry and L. Poljak for critical reading of the manuscript. Our research was supported by the CNRS, Université Paul Sabatier, Toulouse, and by grants from the Région MidiPyrénées, Association pour la Recherche contre le Cancer (to M.C.-F.), la Ligue Nationale contre le Cancer, and la Fondation pour la Recherche Médicale (to T.K).

The publication costs of this article were defrayed in part by payment of page charges. This article must therefore be hereby marked "advertisement" in accordance with 18 USC section 1734 solely to indicate this fact.

\section{Note}

The accession numbers for the snoRNA sequences reported in this paper were deposited in the GenBank data library: U64 (Y11158), U65 (Y11159), U66 (Y11160), U67 (Y11161), U68 (Y11162), U69 (Y11163), U70 (11164), U71a (Y11165), U71b (Y11166), and U72 (11167).

\section{References}

Balakin, A.G., G.S. Schneider, M.S. Corbett, J. Ni, and M.J. Fournier. 1993. snR31, snR32, and snR33: Three novel, nonessential snRNAs from Saccharomyces cerevisiae. Nucleic Acids Res. 21: 5391-5397.

Balakin, A.G., R.A. Lempicki, G.M. Huang, and M.J. Fournier. 1994. Saccharomyces cerevisiae U14 small nuclear RNA has little secondary structure and appears to be produced by post-transcriptional processing. J. Biol. Chem. 269: 739-746.

Balakin, A.G., L. Smith, and M.J. Fournier. 1996. The RNA world of the nucleolus: Two major families of small RNAs defined by different box elements with related functions. Cell 86: 823-834.

Bally, M., J. Hughes, and G. Cesareni. 1988. SnR30: A new, essential small nuclear RNA from Saccharomyces cerevisiae. Nucleic Acids Res. 16: 5291-5303.

Baserga, S.J. and J.A. Steitz. 1991. An intact box C sequence in the U3 snRNA is required for binding of fibrillarin, the protein common to the major family of nucleolar snRNPs. EMBO I. 10: 2645-2651.

Caffarelli, E., A. Fatica, S. Prislei, E. De Gregorio, P. Fragapane, and I. Bozzoni. 1996. Processing of the intron-encoded U16 and U18 snoRNAs: The conserved $\mathrm{C}$ and D boxes control both the processing reaction and the stability of the mature snoRNA. EMBO I. 15: 1121-1131.

Cecconi. F., P. Mariottini, F. Loreni, P. Pierandrei-Amaldi, N. Campioni, and F. Amaldi. 1994. U17 ${ }^{\mathrm{Xs} 8}$, a small nucleolar RNA with a 12 nt complementarity to $18 \mathrm{~S}$ rRNA and coded by a sequence repeated in the six introns of Xenopus laevis ribosomal protein S8 gene. Nucleic Acids Res. 22: 732-741. Cecconi, F., C. Crosio, P. Mariottini, G. Cesareni, M. Giorgi, S. Brenner, and F. Amaldi. 1996. A functional role for some Fugu introns larger than the typical short ones: The example of the gene coding for ribosomal protein S7 and snoRNA U17. Nucleic Acids Res. 24: 3167-3172.

Chu, S., R.H. Archer, J.M. Zengel, and L. Lindahl. 1994. The RNA of RNase MRP is required for normal processing of ribosomal RNA. Proc. Nat1. Acad. Sci. 91: 569-663.

Clark, M.W., M.L.R. Yip, J. Campbell, and J. Abelson. 1990. SSB-1 of the yeast Saccharomyces cerevisiae is a nucleolarspecific, silver-binding protein that is associated with the snR10 and snR11 small nuclear RNAs. J. Cell. Biol. 111: 1741-1751.

Datta, A.K. 1995. Efficient amplification using "megaprimer" by asymmetric polymerase chain reaction. Nucleic Acids Res. 23: 4530-4531.

Eichler, D.C. and N. Craig. 1995. Processing of eukaryotic ribosomal RNA. Prog. Nucleic Acid Res. Mol. Biol. 49: 179-239.

Epstein, P., R. Reddy, and H. Busch. 1984. Multiple states of U3 RNA in Novikoff hepatoma nucleoli. Biochemistry 23: $5421-5425$.

Forster, A.C. and S. Altman. 1990. Similar cage-shaped structures for the RNA components of all ribonuclease $\mathrm{P}$ and ribonuclease MRP enzymes. Cell 62: 407-409.

Girard, J.-P., H. Lehtonen, M. Caizergues-Ferrer, F. Amalric, D. Tollervey, and B. Lapeyre. 1992. GAR1 is an essential small nucleolar RNP protein required for pre-rRNA processing in yeast. EMBO J. 11: 673-682.

Girard, J.-P., C. Bagni, M. Caizergues-Ferrer, F. Amalric, and B. Lapeyre. 1994. Identification of a segment of the small nucleolar ribonucleoprotein-associated protein GAR1 that is sufficient for nucleolar accumulation. I. Biol. Chem. 269: $18499-18506$.

Gold, H.A., J.N. Topper, D.A. Clayton, and J. Craft. 1989. The RNA processing enzyme RNase MRP is identical to the Th RNP and related to RNase P. Science 245: 1377-1380.

Goodall, G.J., K. Wiebauer, and W. Filipowicz. 1990. Analysis of pre-mRNA processing in transfected plant protoplasts. Methods Enzymol. 181: 148-161.

Grandi, P., V. Doye, and E.C. Hurt. 1993. Purification of NSP1 reveals complex formation with nucleoporins and a novel nuclear pore protein NIC96. EMBO I. 12: 3061-3071.

Guthrie, C. and B. Patterson. 1988. Spliceosomal snRNAs. Annu. Rev. Genet. 22: 387-419.

Huang, G.M., A. Jarmolowski, J.C.R. Struck, and M.J. Fournier. 1992. Accumulation of U14 small nuclear RNA in Saccharomyces cerevisiae requires box $\mathrm{C}$, box $\mathrm{D}$, and a $5^{\prime}, 3^{\prime}$ terminal stem. Mol. Cell. Biol. 12: 4456-4463.

Hughes, J.M.X. and M. Ares, Jr. 1991. Depletion of U3 small nucleolar RNA inhibits cleavage in the $5^{\prime}$ external transcribed spacer of yeast pre-ribosomal RNA and impairs formation of 18S ribosomal RNA. EMBO J. 10: 4231-4239.

Jeanteur, P., Amaldi, F., and G. Attardi. 1968. Partial sequence analysis of ribosomal RNA from HeLa cells. II. Evidence for sequences of non-ribosomal type in $45 \mathrm{~S}$ and $32 \mathrm{~S}$ ribosomal RNA precursors. I. Mol. Biol. 33: 757-775.

Kass, S., K. Tyc, J.A. Steitz, and B. Sollner-Webb. 1990. The U3 small nucleolar ribonucleoprotein functions in the first step of preribosomal RNA processing. Cell 60: 897-908.

Kim, N., T. Kato, N. Abe, and S. Kato. 1993. Nucleotide sequence of human cDNA encoding eukaryotic initiation factor 4AI. Nucleic Acids Res. 21: 2012.

Kiss, T. and W. Filipowicz. 1993. Small nucleolar RNAs encoded by introns of the human cell cycle regulatory gene RCC1. EMBO I. 12: 2913-2920. 
1995. Exonucleolytic processing of small nucleolar RNAs from pre-mRNA introns. Genes \& Dev. 9: 1411-1424. Kiss, T., C. Marshallsay, and W. Filipowicz. 1992. 7-2/MRP RNAs in plant and mammalian cells: Association with higher order structures in the nucleolus. EMBO J. 11: 37373746.

Kiss, T., M.-L. Bortolin, and W. Filipowicz. 1996. Characterization of the intron-encoded U19 RNA, a mammalian small nucleolar RNA that is not associated with fibrillarin. Mol. Cell. Biol. 16: 1391-1400.

Kiss-László, Z., Y. Henry, J.-P. Bachellerie, M. Caizergues-Ferrer, and T. Kiss. 1996. Site-specific ribose methylation of preribosomal RNA: A novel function for small nucleolar RNAs. Cell 85: 1077-1088.

Krol, A. and P. Carbon. 1989. A guide for probing native small nuclear RNA and ribonucleoprotein structures. Methods Enzymol. 180: 212-227.

Li, H.V., J. Zagorski, and M.J. Fournier. 1990. Depletion of U14 small nuclear RNA (snR128) disrupts production of $18 \mathrm{~S}$ rRNA in Saccharomyces cervisiae. Mol. Cell. Biol. 10: 11451152.

Lübben, B., C. Marshallsay, N. Rottmann, and R. Lührmann. 1993. Isolation of U3 snoRNP from CHO cells: A novel 55 $\mathrm{kDa}$ protein binds to the central part of U3 snoRNA. Nucleic Acids Res. 21: 5377-5385.

Lübben, B., P. Fabrizio, B. Kastner, and R. Lührmann. 1995. Isolation and characterization of the small nucleolar ribonucleoprotein particle snR30 from Saccharomyces cerevisiae. J. Biol. Chem. 270: 11549-11554.

Lygerou, Z., P. Mitchell, E. Petfalski, B. Séraphin, and D. Tollervey. 1994. The POP1 gene encodes a protein component common to the RNase MRP and RNase P ribonucleoproteins. Genes \& Dev. 8: 1423-1433.

Lygerou, Z., C. Allmang, D. Tollervey, and B. Séraphin. 1996. Accurate processing of a eukaryotic precursor ribosomal RNA by ribonuclease MRP in vitro. Science 272: $268-270$.

Maden, B.E.H. 1990. The numerous modified nucleotides in eukaryotic ribosomal RNA. Prog. Nucleic Acids Res. 39: 241303.

Maxwell, E.S. and M.J. Fournier. 1995. The small nucleolar RNAs. Annu. Rev. Biochem. 35: 897-934.

Mougey, E.B., L.K. Pape, and B. Sollner-Webb. 1993. A U3 small nuclear ribonucleoprotein-requiring processing event in the $5^{\prime}$ external transcribed spacer of Xenopus precursor rRNA. Mol. Cell. Biol. 13: 5990-5998.

Morrissey, J.P. and D. Tollervey. 1993. Yeast snR30 is a small nucleolar RNA required for $18 \mathrm{~S}$ rRNA synthesis. Mol. Cell. Biol. 13: 2469-2477.

Nakasone, K., N. Kenmochi, S. Toku, and T. Tanaka. 1993. The structure of the gene encoding chicken ribosomal protein L30. Biochim. Biophys. Acta 1174: 75-78.

Nicoloso, M., L.-H. Qu, B. Michot, and J.-P. Bachellerie. 1996. Intron-encoded, antisense small nucleolar RNAs: The characterization of nine novel species points to their direct role as guides for the $2^{\prime}$-O-ribose methylation of rRNAs. J. Mol. Biol. 260: 178-195.

Nielsen, H., H. Ørum, and J. Engberg. 1992. A novel class of nucleolar RNAs from Tetrahymena. FEBS Lett. 307:337342.

Nilsson, B., T. Moks, B. Jansson, L. Abrahmsén, A. Elmblad, E. Holmgren, C. Henrichson, T.A. Jones, and M. Uhlén. 1987. A synthetic IgG-binding domain based on staphylococcal protein A. Protein Eng. 1: 107-113.

Peculis, B.A. and J.A. Steitz. 1993. Disruption of U8 nucleolar snRNA inhibits $5.8 \mathrm{~S}$ and $28 \mathrm{~S}$ rRNA processing in the Xenopus oocyte. Cell 73: 1233-1245.
1994. Sequence and structural elements critical for U8 snRNP function in Xenopus oocytes are evolutionarily conserved. Genes \& Dev. 8: 2241-2255.

Perochon-Dorisse, J., F. Chetouani, S. Aurel, N. Iscolo, and B. Michot. 1995. RNA_d2: A computer program for editing and display of RNA secondary structures. Comput. Appl. Biosci. 11: 101-109.

Reddy, R. and H. Busch. 1988. Small nuclear RNAs: RNA sequences, structure, and modifications, In Structure and function of major and minor small nuclear ribonucleoprotein particles. (ed. M.L. Birnstiel), pp. 1-37. Springer-Verlag, Berlin, Germany.

Rimoldi, O.J., B. Raghu, M.K. Nag, and G.L. Eliceiri. 1993. Three new small nucleolar RNAs that are psoralen crosslinked in vivo to unique regions of pre-rRNA. Mol. Cell. Biol. 13: 4382-4390.

Ruff, E.A., O.J. Rimoldi, B. Raghu, and G.L. Eliceiri. 1993. Three small nucleolar RNAs of unique nucleotide sequences. Proc. Natl. Acad. Sci. 90: 635-638.

Samarsky, D.A., A.G. Balakin, and M.J. Fournier. 1995. Characterization of three new snRNAs from Saccharomyces cerevisiae: snR34, snR35 and snR36. Nucleic Acids Res. 23: 2548-2554.

Sambrook, J., E.F. Fritsch, and T. Maniatis. 1989. Molecular cloning: A laboratory manual. Cold Spring Harbor Laboratory Press, Cold Spring Harbor. NY.

Savino, R. and S.A. Gerbi. 1990. In vivo disruption of Xenopus U3 snRNA affects ribosomal RNA processing. EMBO $I$. 9: 2299-2308.

Schimmang, T., D. Tollervey, H. Kern, R. Frank, and E.C. Hurt. 1989. A yeast nucleolar protein related to mammalian fibrillarin is associated with small nucleolar RNA and is essential for viability. EMBO T. 8: 4015-4024.

Schmitt, M.E. and D.A. Clayton. 1993. Nuclear RNase MRP is required for correct processing of pre-5.8S rRNA in Saccharomyces cerevisiae. Mol. Cell. Biol. 13: 7935-7941.

Schmitt, M.E., J.L. Bennett, D.J. Dairaghi, and D.A. Clayton. 1993. Secondary structure of RNase MRP RNA as predicted by phylogenetic comparison. FASEB I. 7: 208-213.

Séraphin, B. 1993. How many intronic snRNAs? Trends Biochem. Sci. 18: 330-331.

Slynn, G., D. Jenner, W. Potts, P. Elvin, J.E. Morten, and A.F. Markham. 1990. Human cDNA sequence homologous to the mouse LLRep3 gene family. Nucleic Acids Res. 18: 681 .

Sollner-Webb, B., K.T. Tycowski, and J.A. Steitz. 1996. Ribosomal RNA processing in eukaryotes. In Ribosomal RNA. Structure, evolution, processing, and function in protein biosynthesis (ed R.A. Zimmermann, and A.E. Dahlberg), pp. 469-490. CRC Press, Boca Raton, FL.

Steele, W.J., N. Okamura, and H. Busch. 1965. Effects of thioacetamide on the composition and biosynthesis of nucleolar and nuclear ribonucleic acid in rat liver. J. Biol. Chem. 240: 1742-1749.

Terns, M.P., C. Grimm, E. Lund, and J.E. Dahlberg. 1995. A common maturation pathway for small nucleolar RNAs. EMBO I. 14: 4860-4871.

Tollervey, D. 1987. A yeast small nuclear RNA is required for normal processing of pre-ribosomal RNA. EMBO I. 6: 41694175.

Tollervey, D. and C. Guthrie. 1985. Deletion of a yeast small nuclear RNA gene impairs growth. EMBO f. 4: 3873-3878.

Tollervey, D. and I.W. Mattaj. 1987. Fungal small nuclear ribonucleoproteins share properties with plant and vertebrate U-snRNPs. EMBO J. 6: 469-476.

Tollervey, D., H. Lehtonen, M. Carmo-Fonseca, and E.C. Hurt. 1991. The small nucleolar RNP protein NOP1 (fibrillarin) is 
Ganot et al.

required for pre-rRNA processing in yeast. $E M B O I .10: 573-$ 584.

Tyc, K. and J.A. Steitz. 1989. U3, U8 and U13 comprise a new class of mammalian snRNPs localized in the cell nucleolus. EMBO J. 8: 3113-3119.

Tycowski, K.T., M.-D. Shu, and J.A. Steitz. 1993. A small nucleolar RNA is processed from an intron of the human gene encoding ribosomal protein S3. Genes \& Dev. 6: 11201130 .

1994. Requirement for intron-encoded U22 small nucleolar RNA in $18 \mathrm{~S}$ ribosomal RNA maturation. Science 266: 1558-1561.

1996. A mammalian gene with introns instead of exons generating stable RNA products. Nature 379: 464-466.

Van den Ouweland, A.M.W., P. Kioschis, M. Verdijk, F. Tamanini, D. Toniolo, A. Poustka, and B.A. van Oost. 1992. Identification and characterization of a new gene in the human Xq28 region. Hum. Mol. Genet. 1: 269.

Venema, J. and D. Tollervey. 1995. Processing of pre-ribosomal RNA in Saccharomyces cerevisiae. Yeast 11: 1629-1650.

Watkins, N.J., R.D. Leverette, L. Xia, M.T. Andrews, and E.S. Maxwell. 1996. Elements essential for processing intronic U14 snoRNA are located at the termini of the mature snoRNA sequence and include conserved nucleotide boxes $\mathrm{C}$ and D. RNA 2: 118-133.

Wiedemann, L.M. and R.P. Perry. 1984. Characterization of the expressed gene and several processed pseudogenes for the mouse ribosomal protein L30 gene family. Mol. Cell. Biol. 4: 2518-2528.

Xia, L., N.J. Watkins, and E.S. Maxwell. 1997. Idenification of specific nucleotide sequences and structural elements required for intronic U14 snoRNA processing. RNA 3: 17-26. 


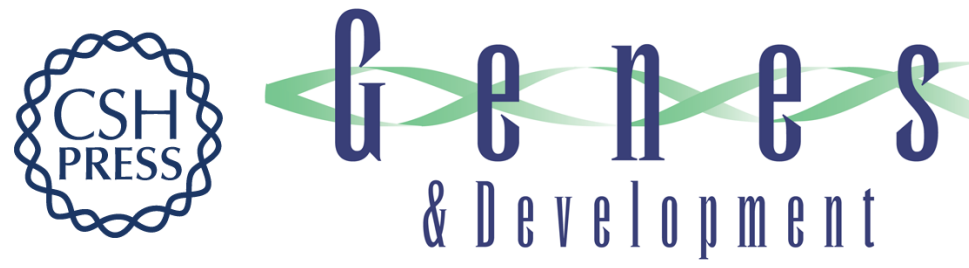

\section{The family of box ACA small nucleolar RNAs is defined by an evolutionarily conserved secondary structure and ubiquitous sequence elements essential for RNA accumulation.}

P Ganot, M Caizergues-Ferrer and T Kiss

Genes Dev. 1997, 11:

Access the most recent version at doi:10.1101/gad.11.7.941

References This article cites 71 articles, 23 of which can be accessed free at: http://genesdev.cshlp.org/content/11/7/941.full.html\#ref-list-1

License

Email Alerting Service

Receive free email alerts when new articles cite this article - sign up in the box at the top right corner of the article or click here.

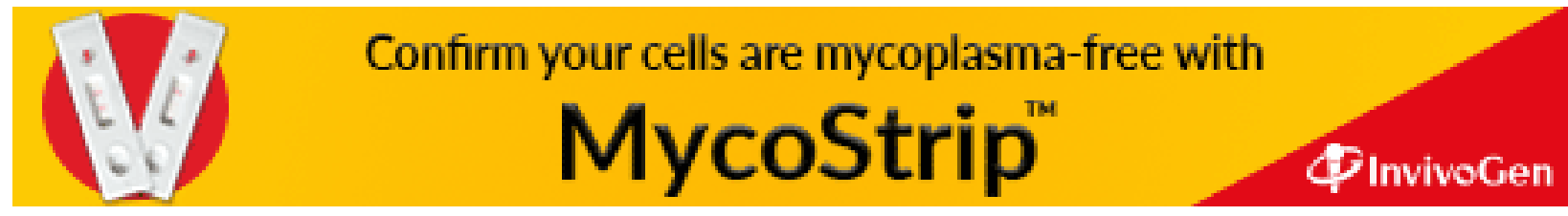

